\title{
Simultaneous Adsorption of Chromium and Acidic Dye from Leather Tannery Model Wastewater Using a Novel Modified Nanoclay
}

\author{
Mahsa Golghasemi Sorkhabi \\ University of Tabriz \\ Fatemeh Notghi Oskui \\ University of Tabriz \\ Afzal Karimi \\ Iran University of medical sciences \\ Mortaza Golizadeh \\ Iran University of medical sciences
}

Hassan Aghdasinia ( $\nabla$ aghdasinia@tabrizu.ac.ir)

University of Tabriz https://orcid.org/0000-0003-3004-8796

\section{Research Article}

Keywords: Simultaneous Adsorption, Chromium, Dye, Modified clay, Response Surface Methodology, Leather Tannery

Posted Date: August 4th, 2021

DOI: https://doi.org/10.21203/rs.3.rs-194098/v1

License: (1) This work is licensed under a Creative Commons Attribution 4.0 International License.

Read Full License

Version of Record: A version of this preprint was published at Environmental Earth Sciences on November 28th, 2021. See the published version at https://doi.org/10.1007/s12665-021-10120-y. 


\section{Simultaneous Adsorption of Chromium and Acidic Dye from Leather Tannery Model Wastewater Using a Novel Modified Nanoclay}

M. Golghasemi Sorkhabi ${ }^{\mathrm{a}}$, H. Aghdasinia ${ }^{\mathrm{a}^{*}}$, F. Notghi Oskui ${ }^{\mathrm{a}}$, A, Karimi ${ }^{\mathrm{b}}$, M. Golizadeh ${ }^{\mathrm{b}}$

${ }^{a}$ Faculty of chemical and petroleum engineering, University of Tabriz, Tabriz, Iran

${ }^{\mathrm{b}}$ Faculty of advanced technologies in medicine, Iran university of medical sciences, 1449614535

Tehran, Iran

* Corresponding author: Hassan Aghdasinia

E-mail address: $\quad$ aghdasinia@tabrizu.ac.ir/ Hassan.Aghdasinia@gmail.com

Tel: +98-41-3339-2931 Fax: +98-41-3333-8497

E-mail addresses of authors:

Mahsa Golghasemi Sorkhabi_ Mahsa.Golghasemi@gmail.com

Fatemeh Notghi Oskui $\quad$ Notghi1992@gmail.com

Afzal Karimi $\quad$ Karimi.af@iums.ac.ir

Mortaza Golizadeh_Ｍor.golizadeh@gmail.com

\section{Acknowledgement}

The authors thank the University of Tabriz (Iran) for the support provided. 


\section{Abstract}

Simultaneous removal of $\mathrm{Cr}^{3+}$ and acidic dye from model tannery wastewater was investigated using local nano clay modified by 3-chloro-2-hydroxypropyltrimethylammonium chloride (CHPTAC) surfactant. X-ray fluorescence (XRF), Fourier transform infrared (FTIR) spectroscopy, X-ray diffraction (XRD), scanning electron microscopy (SEM), carbon, hydrogen, nitrogen and sulfur analysis (CHNS), Brunauer-Emmet-Teller (BET) analysis and pH of zero point charge $\left(\mathrm{pH}_{Z P C}\right)$ analyses were carried out for characterization of the adsorbent, and adsorptive properties of the modified clay were investigated by batch experiments. The effects of essential parameters, such as adsorbent dosage, initial solution $\mathrm{pH}$, initial solution concentration, contact time, and temperature, were studied. Maximum adsorption values (99.74\% for $\mathrm{Cr}^{3+}$ and $83.26 \%$ for dye) were obtained in the following conditions: $\mathrm{pH}$ of 4 , initial concentration of $100 \mathrm{mg} / \mathrm{L}$, adsorbent dosage of $15000 \mathrm{mg} / \mathrm{L}$, contact time of $30 \mathrm{~min}$. The effect of contaminants' concentration was also investigated through response surface methodology (RSM), central composite face-centered (CCF) design and an empirical model was presented. The results of kinetic models' studies demonstrated that simultaneous adsorption of contaminants follows the pseudo-second-order model, and the adsorption data of single and binary solutions fitted nonlinearly to isotherm models showed that the adsorption of $\mathrm{Cr}$ (III) from binary and single solutions follow Langmuir and Dubinin-Radushkevitch (D-R) isotherms, respectively. Adsorption of dye from both single and binary solutions follows Redlich- Peterson (R-PT) isotherm. Maximum adsorption capacities were obtained to be $193.1390 \frac{\mathrm{mg}}{\mathrm{g}}$ and $144.1782 \frac{\mathrm{mg}}{\mathrm{g}}$ for $\mathrm{Cr}^{3+}$ and dye, respectively. Synergistic and antagonistic adsorptions were observed in binary solutions.

Keywords: Simultaneous Adsorption, Chromium, Dye, Modified clay, Response Surface Methodology, Leather Tannery.

\section{Introduction}

In real-life applications, wastewaters contain more than one contaminant, and the contaminants are usually of different chemical and physical properties (Tovar-Gómez et al., 2015; Niu et al., 2018). Heavy metals and dyes are two types of hazardous contaminants that can alter any ecosystem's properties and usually coexist in the effluent of many industries (Deng et al., 2013; Fan et al., 2014; Tovar-Gómez et al., 2015; Aghdasinia and Asiabi, 2018). Chromium 
(III) is an essential heavy metal for human metabolism, but when it enters the body in amounts more than the safe limit, it accumulates in live organs and can be oxidized to chromium (VI), which is a very hazardous heavy metal (Zaroual et al., 2009; Gładysz-Płaska et al., 2012; Seif, Marofi and Mahdavi, 2019). Dyes are widely used in various applications and industries, and it should be noted that about $10 \%$ of the dye used in a process is discharged into the hydrosphere, which is harmful to the environment due to being a visible public concern and a severe threat to human health and aquatic life (Samiey and Toosi, 2010; Yagub et al., 2014; Ahmad et al., 2015). The simultaneous presence of contaminants results in synergetic harm toward human health, animals and plants' lives (Liu et al., 2016). So, investigating the highly efficient methods and techniques for removing contaminants from multi-component solutions is a priority (Deng et al., 2013; Wang et al., 2017). Adsorption is an advantageous and highly efficient method to remove contaminants from wastewaters (Gładysz-Płaska et al., 2012; Fan et al., 2014; Wang et al., 2017; Keçeci, Usta and Uygur, 2020). If the adsorbent could simultaneously remove contaminants, it would reduce operation cost, complexity and equipment investment (Wang et al., 2017). Clays are adsorbents with advantages, such as high cation exchange capacity (CEC), high chemical and mechanical stability, low cost, high abundance and easy manipulation and modification (Srinivasan, 2011; Oskui, Aghdasinia and Sorkhabi, 2019a). Clays are hydrophilic materials with negative surface charge and these properties limit their usage in the removal of various contaminants (Liu et al., 2016). So, proper modifications are used to make them suitable adsorbents for different contaminants. Several methods have been used to modify the adsorptive properties of clays (Srinivasan, 2011; Behnamfard et al., 2019). Modification of clays using organic surfactants prepares them to be used in the removal of organic and hydrophobic materials (Fan et al., 2014; Liu et al., 2016; Heinz et al., 2017; Wang et al., 2017). Several studies have been carried out on the adsorption of different heavy metals and dyes from single-contaminant aqueous solutions via different kinds of clays, but there are only a few studies on the simultaneous removal of heavy metals and dyes by clays (Fan et al., 2014; Stawiński et al., 2017). Furthermore, browsing through literature, one can find the following cases: Wang et al. (2017) modified montmorillonite via trimethyl tetradecyl ammonium chloride ${ }^{1}$, hexadecyl trimethyl ammonium chloride ${ }^{2}$, octadecyl trimethyl ammonium chloride ${ }^{3}$ quaternary ammoniums and cysteamine hydrochloride ${ }^{4}$ modifiers to investigate simultaneous adsorption of phenol and $\mathrm{Zn}^{2+}$ (Wang et al., 2017). Liu et al. (2016) investigated the

\footnotetext{
${ }^{1}$ TTAC

${ }^{2}$ CTAC

${ }^{3}$ STAC

${ }^{4} \mathrm{CSH}$
} 
modification of montmorillonite by amphoteric surfactant of octadecyl dimethyl betaine ${ }^{5}$ to study simultaneous adsorption of $C d^{2+}$ and bisphenol $\mathrm{A}^{6}$ (Liu et al., 2016). Ma et al. (2016) modified montmorillonite by cationic and zwitterionic surfactants of hexadecyltrimethylammonium bromid and hexadecyldimethyl (3-sulphonatopropyl) ammonium, respectively, to simultaneously adsorb Cu (II) and phenol (Ma et al., 2016). Fan et al. (2014) used dodecyl sulfobetaine modified montmorillonite to investigate the simultaneous adsorption of $\mathrm{Cu}^{2+}$ and methylene blue dye (Fan et al., 2014). Gladysz-Plaska et al. (2012) modified natural polish red clay via hexadecyltrimethylammonium bromide $^{7}$ to simultaneously adsorb Cr (VI) and phenol (Gładysz-Płaska et al., 2012). Stawiński et al. (2017) investigated the simultaneous removal of cationic dyes and $\mathrm{Cu}^{2+}$ using vermiculite modified via acid, base and acidbase (Stawiński et al., 2017). In this work, the simultaneous removal of chromium (III) and acid brown from leather tannery model wastewater was thoroughly investigated by a nanoclay modified with 3-chloro-2hydroxypropyltrimethylammonium chloride (CHPTAC) surfactant. The promising results show that this process might yield to a potential method to safely treat the high priority leather tannery wastewater.

\section{Materials and methods}

The local clay used in this study was obtained from Urmia, West Azerbaijan province, North West of Iran. To get a homogeneous size distribution, the clay was sieved and the particles with a smaller size than $845 \mu \mathrm{m}$ were taken for the rest of the experiments. This clay is denoted as U- clay in this paper. The parameter of CEC for U-clay was obtained using the method suggested by Rhoades (Rhoades, 1983; Pansu and Gautheyrou, 2007). The chemical composition and properties of this clay are gathered in Table 1 . Distilled water $(1 \mu$ Siemens $/ \mathrm{cm})$ was used in all experiments. Solutions were prepared by dissolving Chromium (III) chloride hexahydrate $\left(\mathrm{CrCl}_{3} .6 \mathrm{H}_{2} \mathrm{O}\right)$ salt (Samchun, Korea) and acid brown dye (Azar dye, a local Iranian dye company that provides the dyes consumed in the units of leather tannery in the region) in distilled water. Quaternary ammonium solution (3-chloro-2hydroxypropyltrimethylammonium chloride (CHPTAC)) 60 wt. \% in $\mathrm{H}_{2} \mathrm{O}$ was purchased from Sigma-Aldrich.

\footnotetext{
5 BS-18

${ }^{6}$ BPA

${ }^{7}$ HDTMA
} 


\subsection{Adsorbent preparation}

The modified clay was prepared by dissolving a given amount of the surfactant into distilled water and then adding $10 \mathrm{~g}$ of U-clay. The surfactant amount was equivalent to $5 \mathrm{CEC}$ of the U-clay and mass ratio of clay/water was 1:20. The mixture was stirred under $100 \mathrm{rpm}$ using a mechanical stirrer for $24 \mathrm{~h}$ at room temperature. The modified clay was collected and washed for several times with distilled water to remove the $\mathrm{Cl}^{-}$ions. After that, the prepared adsorbent was dried in the oven for $16 \mathrm{~h}$. The modified clay is denoted as CHPTAC-clay in this paper. The adsorbent was ground after drying and was used in the proceeding experiments (Ma et al., 2016).

Table 1: Physical characteristics of the non- modified clay

\begin{tabular}{|c|c|c|c|}
\hline Compound & $\% \mathrm{w} / \mathrm{w}$ & Element & ppm \\
\hline $\mathrm{CaO}$ & 43.23 & As & 0 \\
\hline $\mathrm{SiO}_{2}$ & 13.51 & $\mathrm{Ba}$ & 101 \\
\hline $\mathrm{Al}_{2} \mathrm{O}_{3}$ & 3.03 & $\mathrm{Ce}$ & 0 \\
\hline $\mathrm{Fe}_{2} \mathrm{O}_{3}$ & 1.85 & Co & 4 \\
\hline $\mathrm{MgO}$ & 1.37 & $\mathrm{Cr}$ & 12 \\
\hline $\mathrm{Na}_{2} \mathrm{O}$ & 1.01 & $\mathrm{Cu}$ & 0 \\
\hline $\mathrm{K}_{2} \mathrm{O}$ & 0.66 & $\mathrm{Nb}$ & 1 \\
\hline $\mathrm{TiO}_{2}$ & 0.15 & $\mathrm{Ni}$ & 36 \\
\hline $\mathrm{P}_{2} \mathrm{O}_{5}$ & 0.06 & $\mathrm{~Pb}$ & 12 \\
\hline $\mathrm{MnO}$ & 0.03 & $\mathrm{Rb}$ & 34 \\
\hline $\mathrm{LOI}^{\mathrm{a}}$ at $1100^{\circ} \mathrm{C}$ & 35.1 & $\mathrm{Sr}$ & 454 \\
\hline \multirow{4}{*}{ CEC } & \multirow{4}{*}{$322.4114(\mathrm{mmol} / \mathrm{kg}$ clay $)$} & $\begin{array}{l}\mathrm{V} \\
\mathrm{Y}\end{array}$ & $\begin{array}{l}30 \\
11\end{array}$ \\
\hline & & $\mathrm{Zr}$ & 91 \\
\hline & & $\mathrm{Zn}$ & 41 \\
\hline & & Mo & 26 \\
\hline
\end{tabular}

${ }^{\mathrm{a}}$ Loss of ignition 


\subsection{Adsorbent characterizations}

\subsubsection{X-ray fluorescence (XRF)}

The U-clay chemical composition and elemental analysis were obtained via XRF analysis (Philips, PW1430, Netherland).

\subsection{2. the $\mathrm{pH}$ of zero point charge $\left(\mathrm{pH}_{z p c}\right)$ measurement}

Sodium chloride solutions with a concentration of $0.01 \mathrm{M}$ were prepared. Their pHs were adjusted in the range of 3 to $11.0 .1 \mathrm{~g}$ of the adsorbent was added to $100 \mathrm{ml}$ of each prepared solution. The mixtures were shaken in an incubator (Fanavaran Sahand Azar, 554D, Iran) for $48 \mathrm{~h}$ at the controlled temperature of $25 \pm 0.1^{\circ} \mathrm{C}$. After $48 \mathrm{~h}$, the $\mathrm{pH}$ of the mixtures was measured using a $\mathrm{pH}$ meter. The final $\mathrm{pHs}$ were depicted versus the initial $\mathrm{pHs} . \mathrm{pH}_{z p c}$ was the intercept point of this curve with the diagonal line (Khormaei et al., 2007).

\subsubsection{Fourier transform infrared (FT-IR) spectroscopy}

FT-IR spectra for the non-modified and the modified clays were recorded using a Brucker, TENSOR 27 model (Germany) spectrometer. The spectra range and wavenumber accuracy measured by this spectrometer are 4000-400 $\mathrm{cm}^{-1}$ and $0.1 \mathrm{~cm}^{-1}$, respectively. The readings are carried out at room temperature via $\mathrm{KBr}$ method. The tablets were prepared by the hydraulic press with a radius of $1 \mathrm{~cm}$ and a thickness of $1 \mathrm{~mm}$.

\subsubsection{X-ray diffraction (XRD)}

XRD analysis was carried out by a Panalytical Xpert PRO X-Ray Diffractometer(Xpert Pro MPD model, Netherland). The conditions of measurement were as follows: anode material: $\mathrm{Cu}, 2 \theta$ range: $4.8500^{\circ}-109.9500^{\circ}$, step size: $0.0500^{\circ}$, scan step time: $1.0000 \mathrm{~s}$, divergence slit size: $1.0000^{\circ}$, receiving slit size: $0.1000 \mathrm{~mm}$, measurement temperature: $25^{\circ} \mathrm{C}$. Phase analysis was performed by X'Pert HighScore Plus software. The samples were of random powder.

\subsubsection{Scanning electron microscopy (SEM)}

Morphologies of the non-modified and modified clays were observed using a scanning electron microscopy facilitated with energy-dispersive X-ray spectroscopy (EDX) detector (Philips XL30 ESEM, Netherland). The images were obtained under the operating conditions of $20 \mathrm{kV}$, vacuum pressure of less than $2 \times 10^{-4}$ bar and the electron beam penetration of $1 \mu$. Using EDX, elements after Na were detectable. 


\subsubsection{CHNS analysis}

Elemental analysis of C, H, N and S were performed in Elementar Vario EL III (Laos) analyzer. Using this analysis, the concentration of CHPTAC loaded on the organoclay was calculated using the following equation(Gładysz-Płaska et al., 2012):

$$
\begin{gathered}
c_{C H P T A C}=\frac{c_{m}}{1-c_{m} \cdot M W} \\
c_{m}=\frac{c_{N}}{n_{N} \cdot M_{N} \cdot 100}
\end{gathered}
$$

In which $c_{m}$ is the molar concentration of CHPTAC in the organoclay $(\mathrm{mol} / \mathrm{g})$ and MW is the molecular weight of the surfactant $(\mathrm{g} / \mathrm{mol}) . c_{N}$ is the nitrogen content in the sample in weight percent, $n_{N}$ is the number of nitrogen atoms in the surfactant and $M_{N}$ the molecular mass of $\mathrm{N}$.

$c_{m}$ was calculated from equation 2 and was inserted to the equation 1 and $c_{C H P T A C}$, the concentration of CHPTAC loaded on the clay, was calculated.

\subsection{7. $N_{2}$ adsorption and desorption}

$N_{2}$ adsorption and desorption were performed for non-modified and modified clays via Specific Surface Area and Porosity Analyzer PHS-1020 (PHSCHINA) using liquid nitrogen with the temperature of $77 \mathrm{~K}$. Brunauer-EmmetTeller (BET) equation and Barret-Joyner-Halenda (BJH), dBJH and MP-plot methods were applied to obtain the specific surface area and pore size distribution, respectively.

\subsection{Adsorption processes}

To study the adsorptive properties of CHPTAC- clay, all effective parameters were investigated using one factor at a time method in batch experiments. Five steps were included in the adsorption studies: (1) determination of the adsorbent's amount, (2) the $\mathrm{pH}$ effect studies, (3) the initial solution concentration effects, (4) studies on the contact time and (5) investigation of the temperature effect on the simultaneous adsorption of contaminants. The experiments were carried out using $100 \mathrm{ml}$ of the solutions on magnetic stirrers. The range of each parameter was as follows: 2500 to $20000 \mathrm{mg} / \mathrm{L}$ for adsorbent dosage, 3 to 5 for the initial $\mathrm{pH}$ of solutions, 25 to $300 \mathrm{mg} / \mathrm{L}$ for the initial concentration of the contaminants, 1.5 to $240 \mathrm{~min}$ of contact time and temperatures of 15 to $45^{\circ} \mathrm{C}$. All these experiments were carried out for binary solutions. After each experiment, the mixture was centrifuged at $4000 \mathrm{rpm}$ for 15 minutes and the 
concentrations of the Chromium and dye were measured by atomic absorption spectroscopy (AAS) (Analytikjena, novAA 400 P model, Germany) and ultraviolet-visible (UV-Vis) spectroscopy (Hanon, China), respectively. Adsorption efficiency and adsorption capacity were calculated using the following equations:

$$
\begin{aligned}
& \text { Removal efficiency }(\%)=\frac{C_{0}-C_{e}}{C_{0}} * 100 \\
& q_{e}=\frac{V}{m}\left(C_{0}-C_{e}\right)
\end{aligned}
$$

Where, $q_{e}$ is the equilibrium adsorption capacity of the adsorbent $(\mathrm{mg} / \mathrm{g}), V$ is the volume of the solution $(L), m$ is the mass of adsorbent $(\mathrm{g}), C_{0}$ is the adsorbate's initial concentration $(\mathrm{mg} / \mathrm{L}), C_{e}$ is the equilibrium concentration of adsorbate $(\mathrm{mg} / \mathrm{L})$ (Limousin et al., 2007).

However, to study the synergistic and/or antagonistic effects in simultaneous adsorption in binary systems, adsorption of the contaminants from monocomponent solutions in the range of 25 to $300 \mathrm{mg} / \mathrm{L}$ were also investigated and the results were compared with the results of adsorption capacities from binary solutions via the parameter of $R_{q, i}$, which is defined as (Tovar-Gomez et al., 2012):

$$
R_{q, i}=\frac{q_{b, i}}{q_{s, i}}
$$

Where $q_{b, i}$ and $q_{s, i}$ are the adsorption capacity of component $i$ from the binary and single solutions $(\mathrm{mg} / \mathrm{g})$, respectively.

Kinetic models of pseudo-first-order (Eq.6) and pseudo-second-order (Eq.7) were linearly fitted to the obtained data.

$$
\begin{aligned}
& \quad \ln \left(q_{e}-q_{t}\right)=\ln q_{e}-k_{1} t \\
& \frac{t}{q_{t}}=\frac{1}{k_{2} q_{e}^{2}}+\frac{1}{q_{e}} t \\
& h=k_{2} q_{e}^{2}
\end{aligned}
$$

Where $K_{1}$ is the rate constant of the pseudo-first-order model $(1 / \mathrm{min}), K_{2}$ is the rate constant of the pseudo-secondorder kinetic model $(\mathrm{g} / \mathrm{mg} \mathrm{min}), q_{t}$ is the amount of adsorbed adsorbent $(\mathrm{mg} / \mathrm{g})$ at time $t$ and $h$ (Eq.8) gives the value of the initial velocity of the adsorption (Kim et al., 2004; Ho, 2006; El-Ashtoukhy, Amin and Abdelwahab, 2008). 
Adsorption modeling is a fundamental topic for engineering the wastewater treatment processes (for operation, design and optimization). Two parameter isotherm models of Langmuir (Eq.9) and Freundlich (Eq.10) and three-parameter isotherm models of Dubinin-Radushkevich (D-R) (Eq.11) and Redlich-Peterson (R-PT) (Eq.12) were non-linearly fitted to the adsorption data of the single and binary solutions via minimization of error functions of the sum of square errors (SSE), (Eq.13), the fractional HYBRID (Eq.14) and the nonlinear chi-square (Eq.15) using Add-in solver tool in Microsoft Excel. The equations of the isotherms and the error functions used are as follows (Allen et al., 2003; Wong et al., 2004; Foo and Hameed, 2010):

$$
\begin{aligned}
& q_{e}=\frac{q_{m L} b C_{e}}{1+b C_{e}} \\
& q_{e}=K_{F} C_{e}^{1 / n_{F}} \\
& q_{e}=q_{S D} \exp \left(-K_{a d} \varepsilon^{2}\right) \\
& q_{e}=\frac{K_{R} C_{e}}{1+a_{R} C_{e}^{g}} \\
& S S E=\sum_{i=1}^{n}\left(q_{e, \text { cal }}-q_{e, \text { meas }}\right)_{i}^{2} \\
& H Y B R I D=\frac{100}{n-p} \sum_{i=1}^{n}\left(\frac{\left(q_{e, c a l}-q_{e, \text { meas }}\right)^{2}}{q_{e, \text { meas }}}\right)_{i} \\
& \chi^{2}=\sum_{i=1}^{n}\left(\frac{\left(q_{e, \text { cal }}-q_{e, \text { meas }}\right)^{2}}{q_{e, m e a s}}\right)_{i}
\end{aligned}
$$

Where $q_{m L}$ is the Langmuir maximum adsorption capacity of the adsorbent $(\mathrm{mg} / \mathrm{g}), b$ is the Langmuir equilibrium constant $(L / m g), K_{F}$ is the Freundlich constant $\left(m g^{1-n} L^{n} / g\right), n_{F}$ is the Freundlich constant, $q_{S D}$ is the D-R theoretical isotherm saturation capacity $(m g / g), K_{a d}$ is the D-R isotherm constant related to the adsorption energy $\left(m o l^{2} / \mathrm{kJ}^{2}\right)$ related to the mean adsorption $\operatorname{energy}(E)(\mathrm{Eq} .16), \gamma$ is the Polanyi potential, Eq.17, $K_{R}$ is the R-PT isotherm constant $(L / g), a_{R}$ is the R-PT isotherm constant $(L / m g)$ and $g$ is the R-PT isotherm exponent (Foo and Hameed, 2010; Parimal, Prasad and Bhaskar, 2010).

$$
E=\frac{1}{\sqrt{2 K_{a d}}}
$$




$$
\gamma=R T \ln \left(1+\frac{1}{C_{e}}\right)
$$

$R_{L}$ (separation factor) is a dimensionless constant and the main characteristic of the Langmuir isotherm:

$$
R_{L}=\frac{1}{1+b C_{0}}
$$

Where $\mathrm{b}$ is the constant of the Langmuir isotherm $(L / m g)$ and $C_{0}$ is the initial concentration of the contaminant $(\mathrm{mg} / \mathrm{L}) . R_{L}>1, R_{L}<1, R_{L}=1$ and $R_{L}=0$ indicate unfavorable, favorable, linear and non-reversible adsorptions, respectively (Hameed, Mahmoud and Ahmad, 2008).

Thermodynamic parameters of variations of free Gibbs energy $\left(\Delta G^{\circ}\right)$, variations of enthalpy $\left(\Delta H^{\circ}\right)$ and variations of entropy $\left(\Delta S^{\circ}\right)$ were also calculated using the equations below (Fil, Ozmetin and Korkmaz, 2012; Elmoubarki et al., 2015):

$$
\begin{aligned}
& \Delta G^{0}=-R T \ln \left(K_{D}\right) \\
& K_{D}=\frac{q_{e}}{C_{e}} \\
& \quad \ln K_{D}=-\frac{\Delta G^{0}}{R T}=-\frac{\Delta H^{0}}{R T}+\frac{\Delta S^{0}}{R}
\end{aligned}
$$

Where $K_{D}$ is the thermodynamic distribution coefficient (Eq.20).

\subsection{Response surface methodology (RSM)}

Differences in adsorbates' concentration in systems having more than one contaminant may result in variations in adsorption capacities. To study the effect of contaminants' concentration on the adsorption capacity of each contaminant, RSM, face-centered central composite design (CCD), by the Design Expert 10.0.7 software was used (Tovar-Gómez et al., 2015). The initial concentration of the chromium and dye were considered as two independent variables ( $x_{1}$ and $x_{2}$ are coded variables). In CCF design, each variable takes levels of $\pm \alpha, \pm 1$ and 0 , which are 250, 50 and 150, respectively. This method gives a quadratic equation that can predict the adsorption capacities. The equation is as follows:

$$
Y=\beta_{0}+\sum_{i=1}^{n} \beta_{i} X_{i}+\sum_{i=1}^{n} \beta_{i i} X_{i}^{2}+\sum_{i=1}^{n-1} \sum_{j=2}^{n} \beta_{i j} X_{i} X_{j} \pm \varepsilon
$$


Where $Y$ is the predicted response or output (depended variable), $n$ is the number of the patterns, $i$ and $j$ are the index numbers for pattern, $X_{i}, X_{j}, \ldots, X_{n}$ are the input coded variables that affect the response $Y, X_{i}^{2}, X_{j}^{2}, \ldots, X_{n}^{2}$ are the square effects, $X_{i} X_{j}, X_{i} X_{n}$ and $X_{j} X_{n}$ are the interaction effects, $\beta_{0}$ is the free or offset term called intercept term, $\beta_{i}$ $(i=1,2, \ldots, n)$ is the linear (first-order) main effect, $\beta_{i i}(i=1,2, \ldots, n)$ is the squared (quadratic) effect, $\beta_{i j}(i=$ $1,2, \ldots, n ; j=1,2, \ldots, n)$ is the interaction effect and $\varepsilon$ is a random error or allows for discrepancies or uncertainties between the predicted and measured values (Oskui, Aghdasinia and Sorkhabi, 2019b).

\section{Results and discussion}

The "results and discussion" section contains nine sub-sections of adsorbent characterizations, adsorption processes, adsorption selectivity, kinetic, isotherm, thermodynamic and RSM studies, adsorption mechanism and comparison of the results with literature data.

\subsection{Adsorbent characterizations}

\subsection{1. $\mathrm{pH}_{z p c}$}

The $\mathrm{pH}$ zero-point charge plays an important role in the adsorption process. $p H_{z p c}$ values were obtained to be 9.75 and 8.6 for U-clay and CHPTAC-clay, respectively. In each adsorbent, for $\mathrm{pH}$ values higher than these, the adsorbents have a negative charge, and in $\mathrm{pH}$ values lower than these, the adsorbents have a positive charge (Wang et al., 2017). Figure 1 depicts the results of this analysis. 


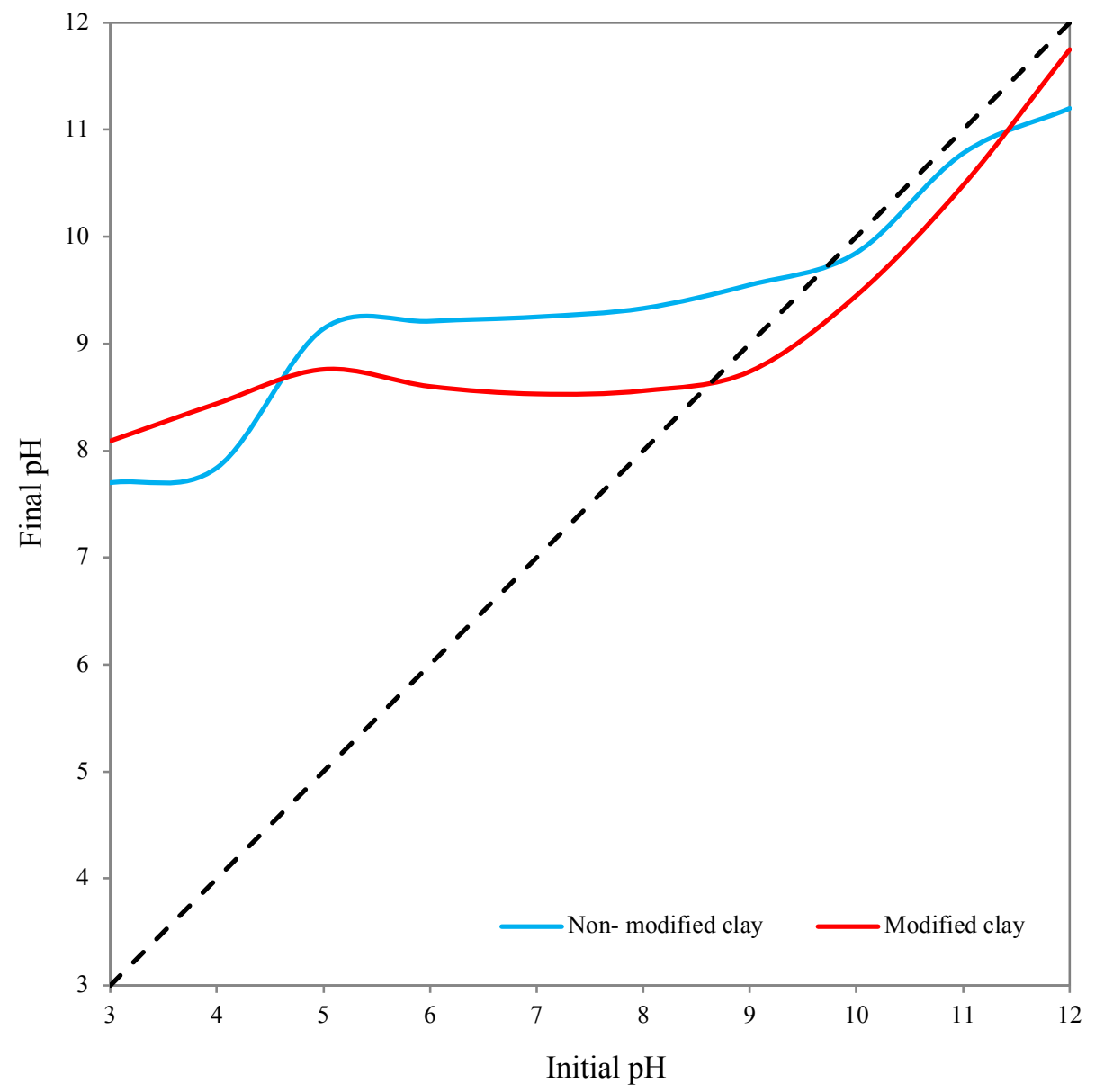

Fig. 1: Final pH versus initial pH of non-modified and modified clay

\subsubsection{FTIR}

Eventhough the $O-H$ stretching region is perhaps the most important diagnostic part of the spectrum, the positive identification of as many characteristic bands of individual minerals as possible in the whole $4000-400 \mathrm{~cm}^{-1}$ range is needed to recognize the mineral species. In the studies of clay minerals, the absorption bands, due to structural $\mathrm{OH}$ and $\mathrm{Si}-\mathrm{O}$ groups, play an important role in the differentiation of clay minerals from each other. The $4000-3000 \mathrm{~cm}^{-1}$ range corresponds to $O-H$ stretching vibrations and $1300-400 \mathrm{~cm}^{-1}$ range in the spectra of the clay minerals show $\mathrm{Si}-\mathrm{O}$ stretching and bending as well as $O-H$ bending absorptions.

Based on the thorough investigations carried out by researchers, the IR spectra of dioctahedral smectites show only a single band in the $O-H$ stretching region. A broad band near $3430 \mathrm{~cm}^{-1}$, observed somewhat clearly in the spectra of all smectites, is due to $\mathrm{H}-\mathrm{O}-\mathrm{H}$ vibrations of the adsorbed water. The spectrum of the untreated sample shows 
intensive bands at $1030 \mathrm{~cm}$ attributed to the $\mathrm{Si}-\mathrm{O}$ stretching vibrations, the $790 \mathrm{~cm}^{-1}$ band represents the $\mathrm{Si}-O$ stretching of quartz and silica and the 520 and $470 \mathrm{~cm}^{-1}$ bands are assigned to $\mathrm{Si}-\mathrm{O}-\mathrm{Al}$ (octahedral $\mathrm{Al}$ ) and $\mathrm{Si}-\mathrm{O}-\mathrm{Si}$ bending vibrations, respectively.

Various arrangement within the layers (1:1 versus 2:1 and/or di- versus trioctahedral character) is reflected in the shape and positions of the bands. While the $\mathrm{Si}-\mathrm{O}$ stretching vibrations of kaolinite and dickite give several wellresolved strong bands in the $1120-1000 \mathrm{~cm}^{-1}$ region, the main $\mathrm{Si}-\mathrm{O}$ band of chrysotile is observed at a lower frequency of $960 \mathrm{~cm}^{-1}$. Only one broad complex $\mathrm{Si}-\mathrm{O}$ stretching band is present in the IR spectra of both di- and trioctahedral smectites. Montmorillonite and nontronite absorb at 1030 and $1019 \mathrm{~cm}^{-1}$, respectively, while for hectorite and saponite the absorption is seen at 1012 and $1009 \mathrm{~cm}^{-1}$, respectively.

The position of the $O-H$ bending bands is strongly influenced by the occupancy of the octahedral sheet in both 1:1 or in 2:1 minerals. Thus, the dioctahedral minerals absorb in the $950-800 \mathrm{~cm}^{-1}$ region, while the $\mathrm{OH}$ absorption of the trioctahedral minerals is shifted to lower frequencies, the $700-600 \mathrm{~cm}^{-1}$ range.

Due to many applications of these modified minerals, organo-clays, researchers studied the interactions between the clay minerals and the organic molecules.

The $C-H$ stretching bands of the alkylammonium cations occur in the $3020-2800 \mathrm{~cm}^{-1}$ region. The bands in $1580-$ $1650 \mathrm{~cm}^{-1}$ represent the $N-H$ bending. The spectrum of CHPTAC-clay shows a band near $3620 \mathrm{~cm}^{-1}$ owing to the stretching vibrations of the structural $\mathrm{OH}$ groups, and a broad band near $3440 \mathrm{~cm}^{-1}$ due to the $O-H$ stretching vibrations of the present $\mathrm{H}_{2} \mathrm{O}$ in the smectite.

The hydrophilic surface of clay minerals can be turned hydrophobic by replacing the naturally occurring inorganic cations with various alkyl- and/or aryl-organocations. An important consequence of this replacement is that the clay surface takes on hydrophobic character, which greatly enhances their affinity for organic pollutants (Madejová, 2003; Adikary and Wanasinghe, 2012; Tahir, Sultan and Qadir, 2013; Çakmak et al., 2017; El Kassimi et al., 2021; Namjoufar, Farzi and Karimi, 2021). 


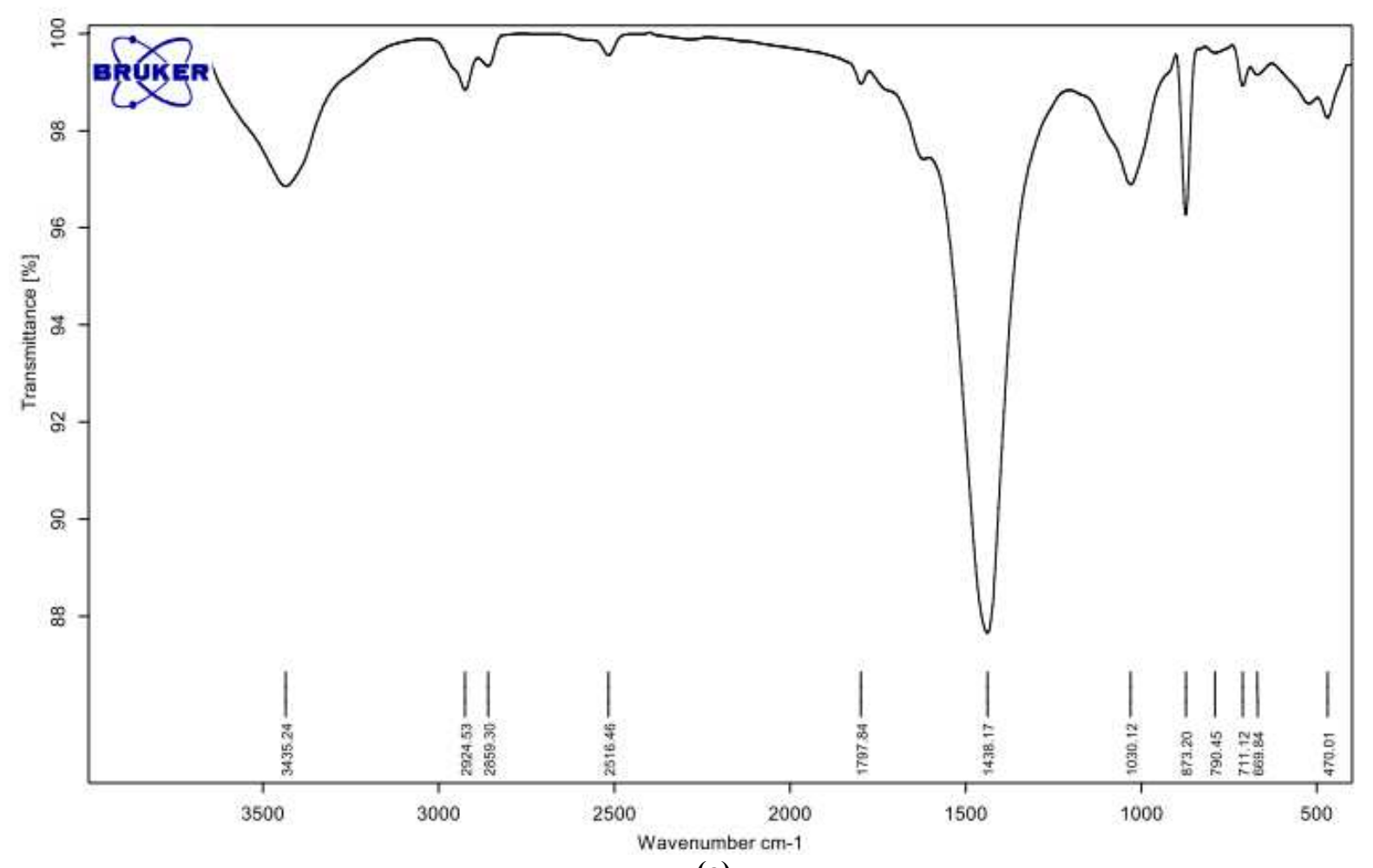

(a)

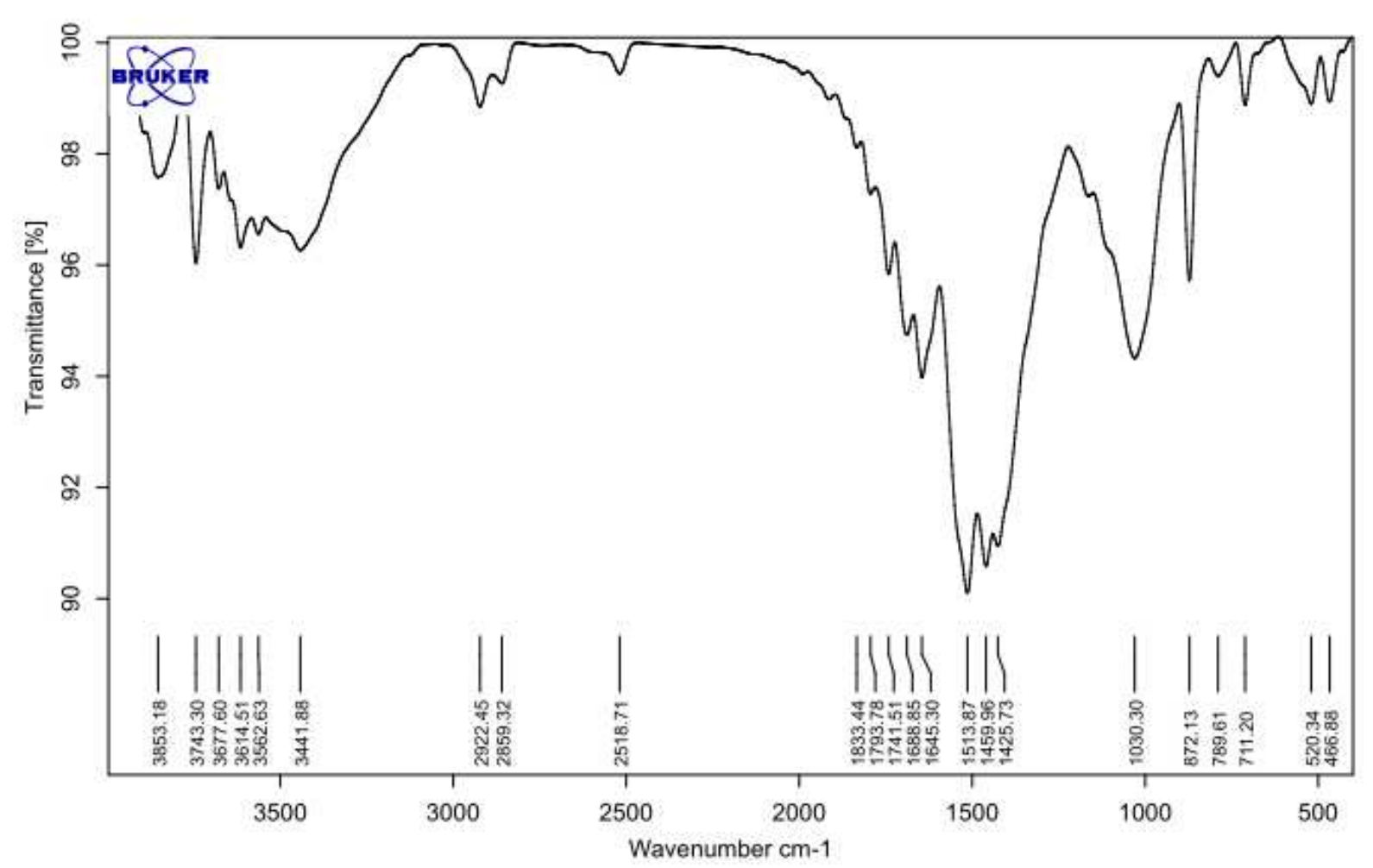

(b)

Fig. 2: The FT-IR spectra of (a) non- modified and (b) modified clay 


\subsubsection{XRD}

Figure 3 depicts the XRD spectra of the non-modified and surfactant-modified clays. Based on the full report from the XRD analysis and the reported $2 \theta$, the adsorbent has calcium carbonate $\mathrm{Ca}\left(\mathrm{CO}_{3}\right)$ (calcite) and silicon oxide $\mathrm{SiO}_{2}$ (quartz). This finding is in full consistent with FTIR results. High value of Loss on ignition or LOI (35.1\%), in XRF is also related to the presence of carbonate and silicate minerals (El Kassimi et al., 2021).

The introduction of the surfactant into the clay resulted in the elimination of some peaks. The modification leads to a low increment of d- spacing in the modified clay (Ma et al., 2016).

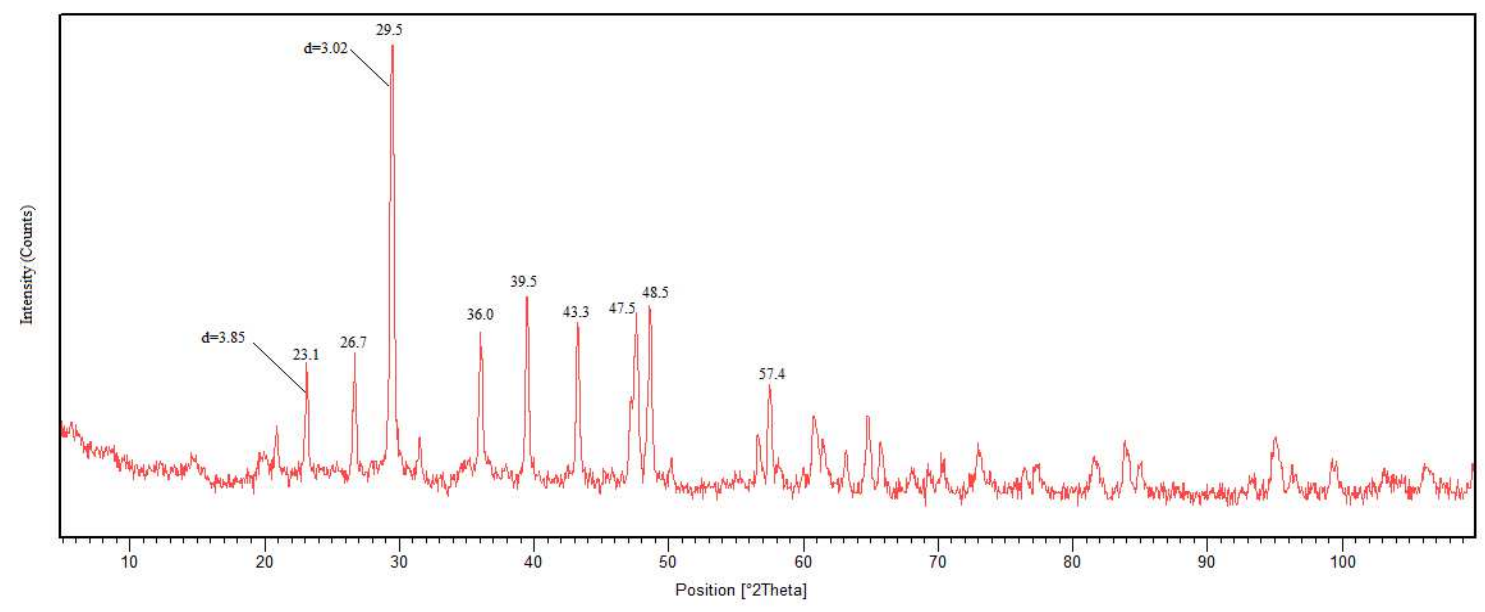

(a)

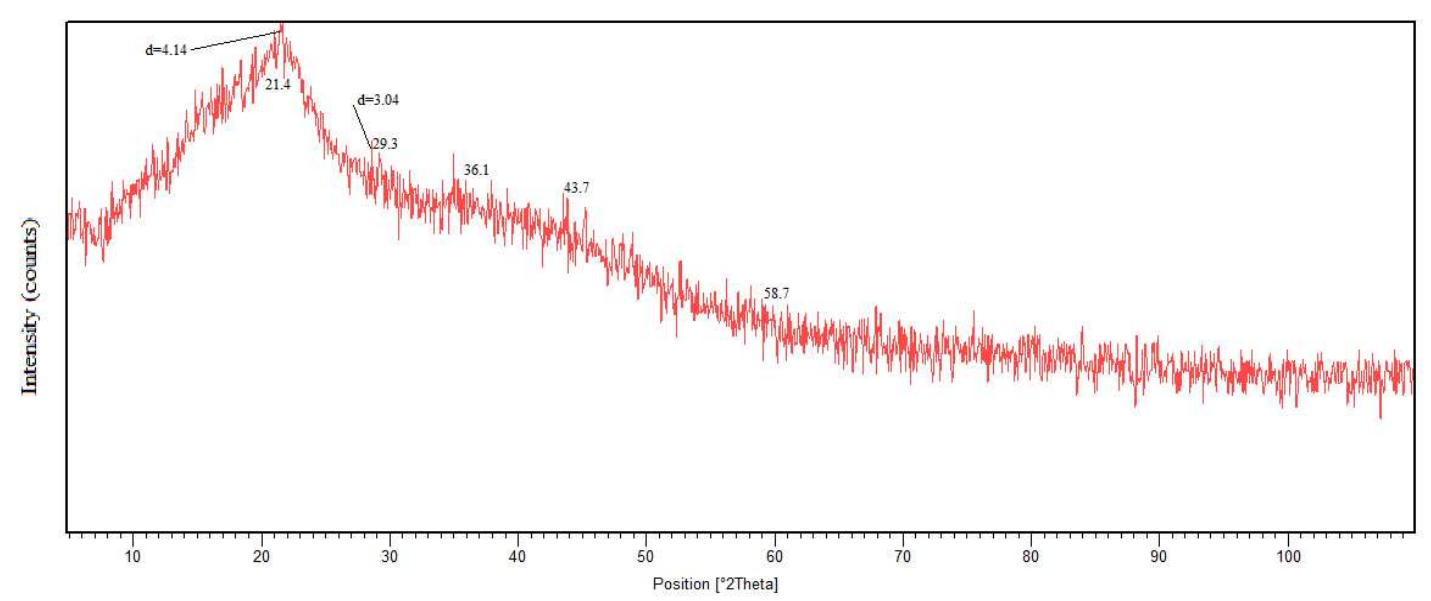

(b)

Fig. 3: XRD patterns of (a) non-modified and (b) modified clay 


\subsubsection{SEM}

Figure 4 shows the SEM images of the non-modified and modified clays. SEM images are used as a proof of concept to observe the porous structure of the U-clay and CHPTAC-clay. The images show that the smoother surface of the U-clay has become more porous (Wang et al., 2016). For a more detailed, thorough and quantitative result on the structures, BET test was also carried out for both modified and non-modified clays. And the results of this analysis confirms the increase in porosity. Using EDX analysis, elements present in the adsorbent after modification were also investigated and the results are demonstrated in Fig.4 (e). 


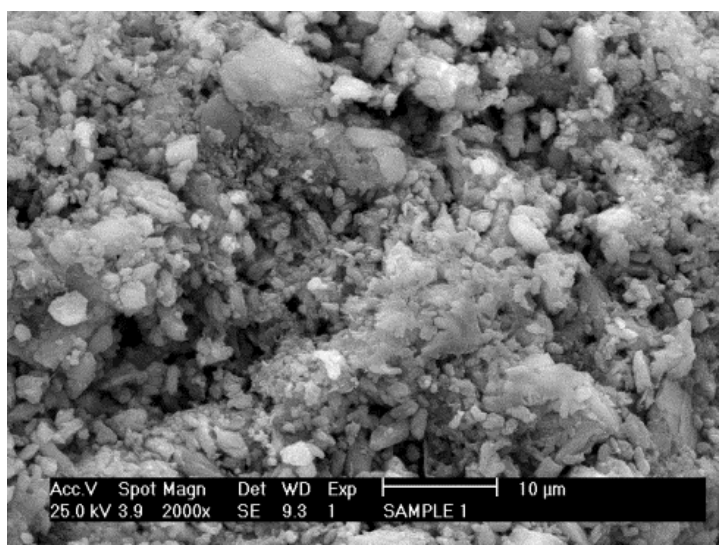

(a)

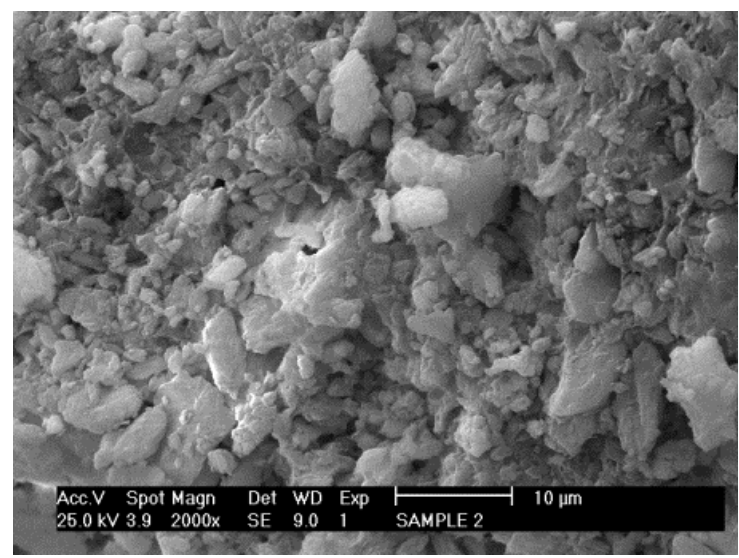

(c)

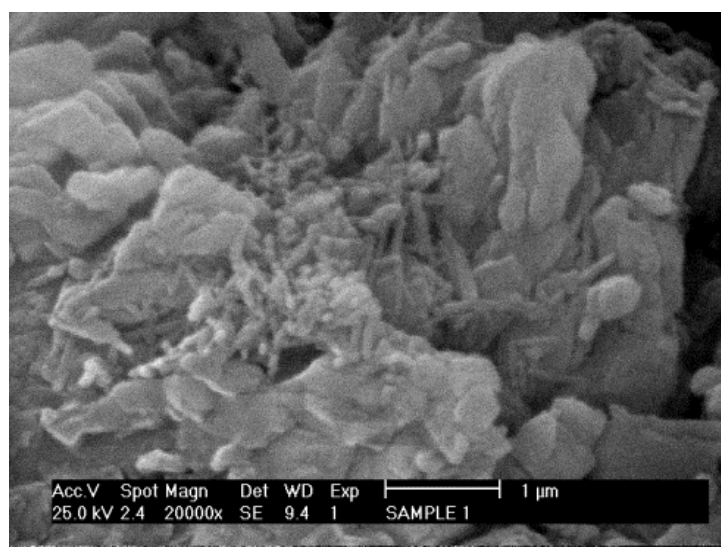

(b)

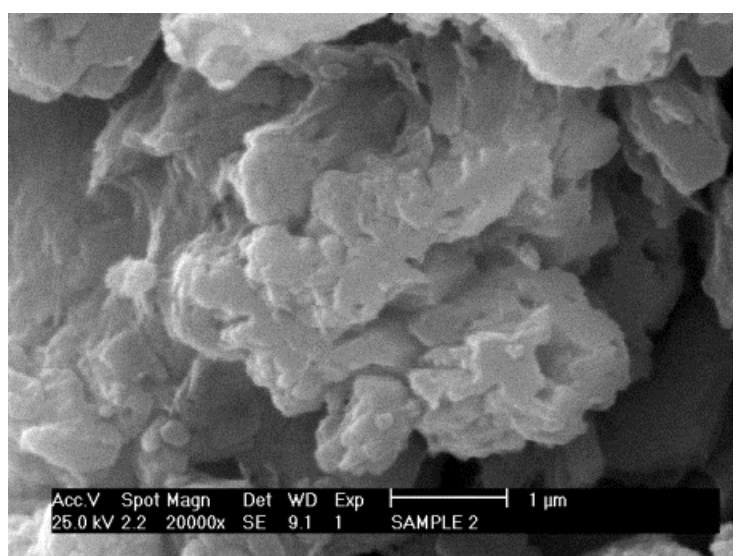

(d)

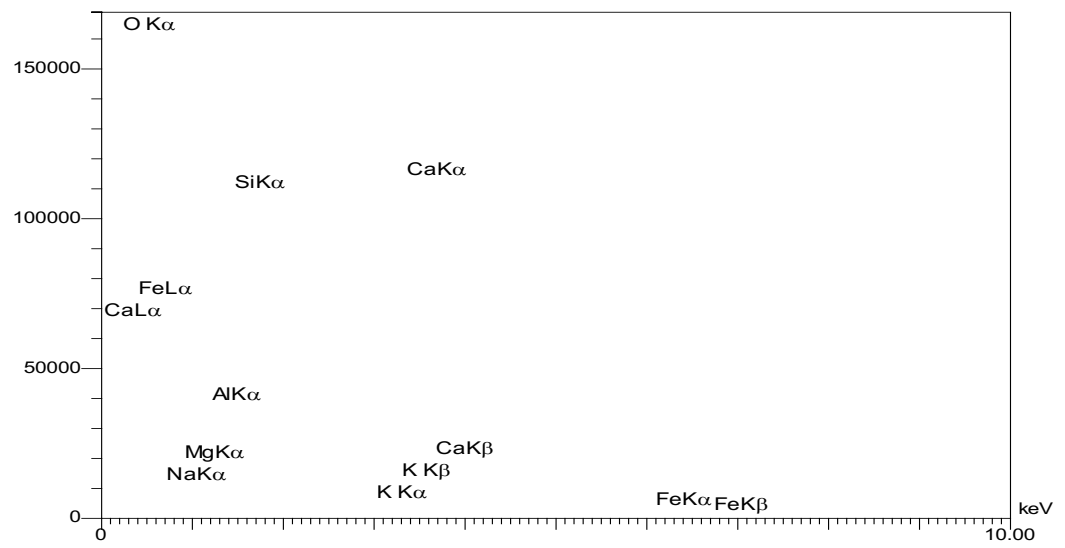

(e)

Fig. 4: SEM images of (a) non-modified clay, 10 $\mu \mathrm{m}$, (b) non-modified clay, $1 \mu \mathrm{m}$, (c) modified clay, $10 \mu \mathrm{m}$, (d) modified clay, $1 \mu \mathrm{m}$ and (e) EDX analysis of the modified clay 


\subsubsection{CHNS analysis}

Using CHNS analysis data and by applying Equations 1 and 2, $C_{C H P T A C}$ was calculated to be $0.1703 \mathrm{mmol} / \mathrm{g}, 52.55$ $\%$ of CEC.

\subsection{6. $N_{2}$ adsorption and desorption}

The data obtained by this analysis are shown in Table 2 . The results show that the average pore diameter reduces, some mesopores become micropores, and the total pore volume after modification of the U-clay was significantly incremented. A significant increase was seen in the specific surface area value in the CHPTAC- clay, compared to the U-clay, which is consistent with the result of mesopores becoming micropores. This high increase in the specific surface area may be attributed to the cation exchange of the ions present in the structure with the long-chain alkylammonium cations. Also, mesopores volume was increased after the modification, but the mesopores' radii were constant.

Table 2: Porous properties of non-modified and modified clays

\begin{tabular}{lll}
\hline Samples & Non- modified clay & Modified clay \\
\hline Specific surface area $\left(\mathrm{m}^{2} / \mathrm{g}\right)$ & 20.015 & 336.871 \\
Total pore volume $\left(\mathrm{cm}^{3} / \mathrm{g}\right)$ & 0.032415 & 0.496 \\
Average pore diameter $(\mathrm{nm})$ & 6.4782 & 0.7 \\
Maximum radius of mesepores & 1.21 & 1.26 \\
$(\mathrm{~nm})$ & & 1.197 \\
Mesepores volume $\left(\mathrm{cm}^{3} / \mathrm{g}\right)$ & 0.028815 & \\
\hline
\end{tabular}




\subsection{Adsorption processes}

\subsubsection{Effect of adsorbent dosage}

To find the effect of adsorbent dosage, $0.25 \mathrm{~g}$ to $2 \mathrm{~g}$ of CHPTAC- clay was applied to solutions of $100 \mathrm{ml}$ in $\mathrm{pH}$ of 4 , containing $100 \mathrm{mg} / \mathrm{L}$ of each contaminant, and a contact time of $2 \mathrm{hr}$ was given. The results are depicted in Figure 5 (a). As shown in this figure, the adsorbent values of 5000 to $15000 \frac{\mathrm{mg}}{\mathrm{L}}$ lead to the maximum removal of $\mathrm{Cr}$ (III) and dye, respectively. For each contaminant, when the adsorbent value was lower than this, a lower removal was obtained, showing that there were not enough adsorbent and adsorption sites available for contaminants. For Cr (III), the adsorbent values up to $15000 \frac{\mathrm{mg}}{\mathrm{L}}$ resulted in a constant removal value of $99 \%$, and then the removal efficiency was decreased. For the dye, up to $15000 \frac{\mathrm{mg}}{\mathrm{L}}$, an increase in removal efficiency was seen, and afterward, the efficiency decreased. Agglomeration of the adsorbent was the reason for this decrease in the removal efficiency (Hafshejani $e t$ al., 2015). The adsorbent value of $15000 \frac{\mathrm{mg}}{\mathrm{L}}$ was the value chosen to be applied in the upcoming experiments.

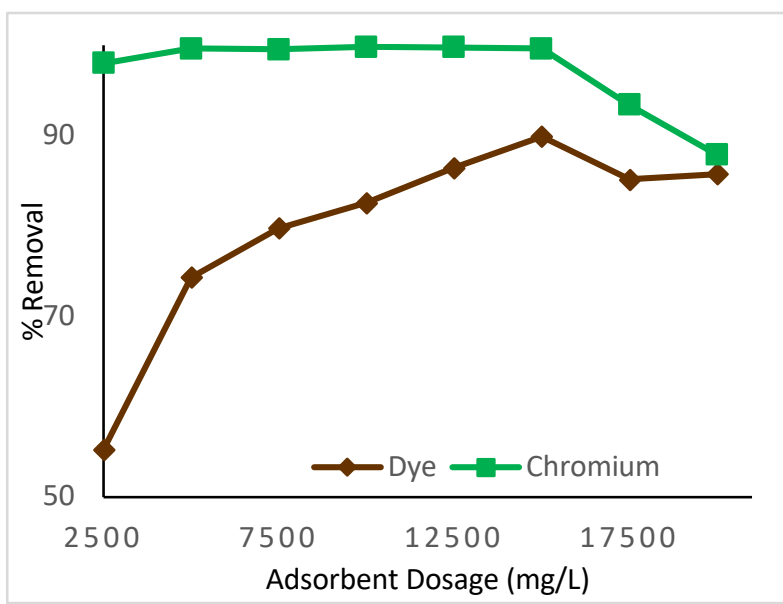

(a)

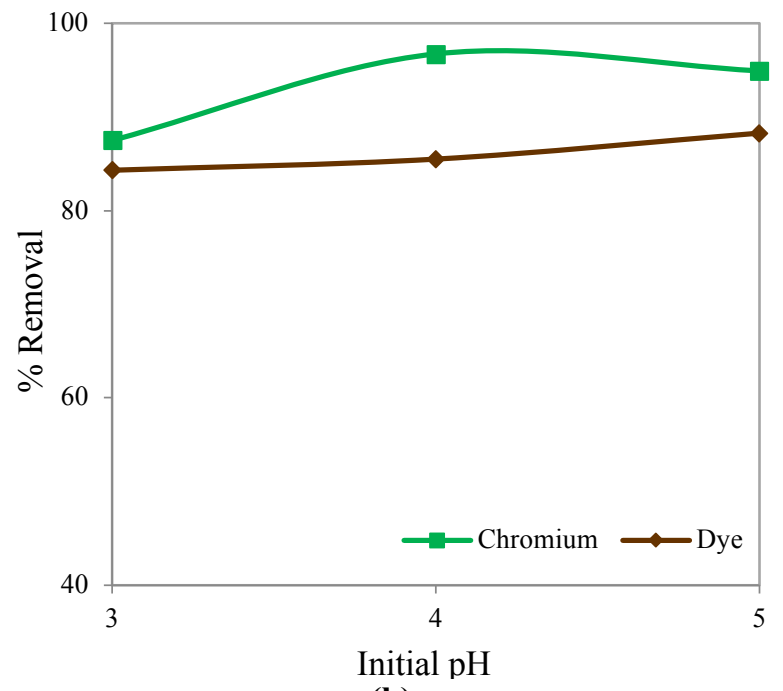

(b) 


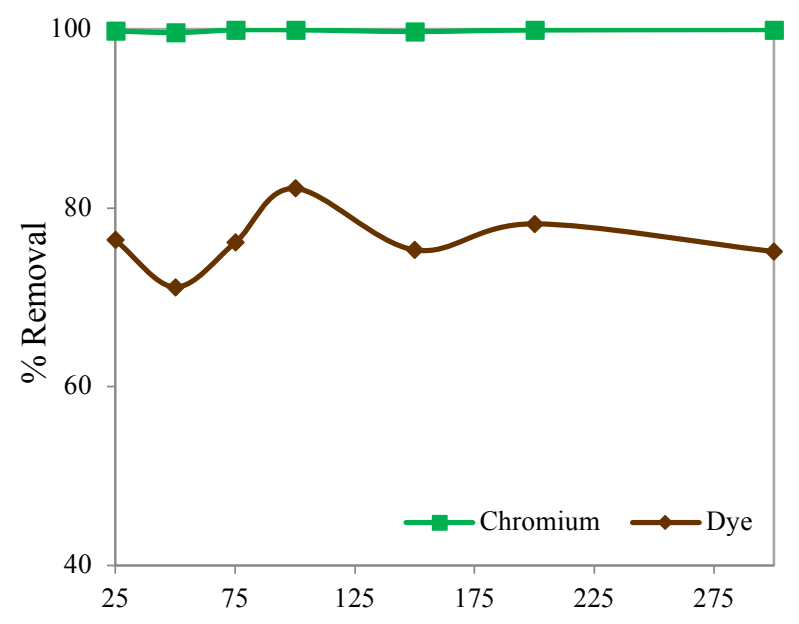

Initial $\mathrm{Cr}$ (III) and dye concentration (mg/L)

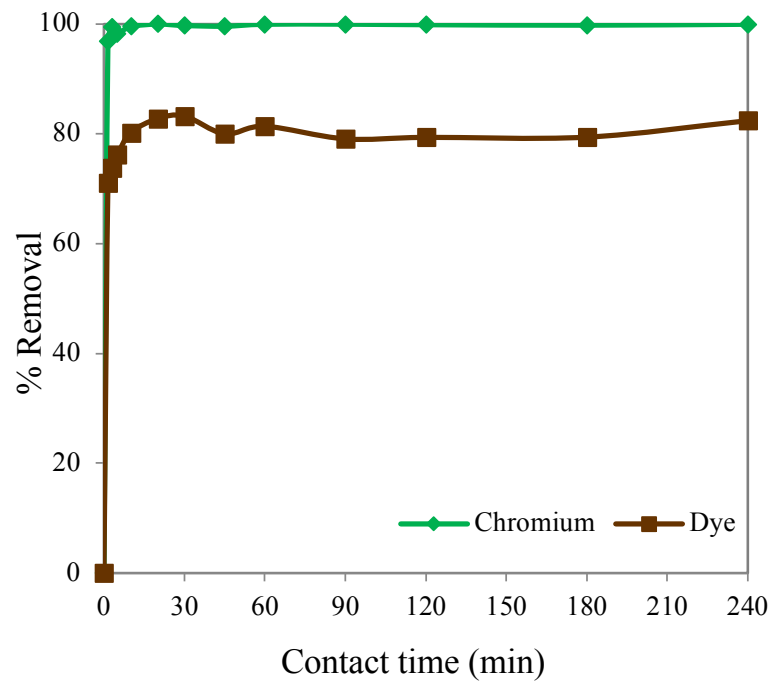

(d)

(c)

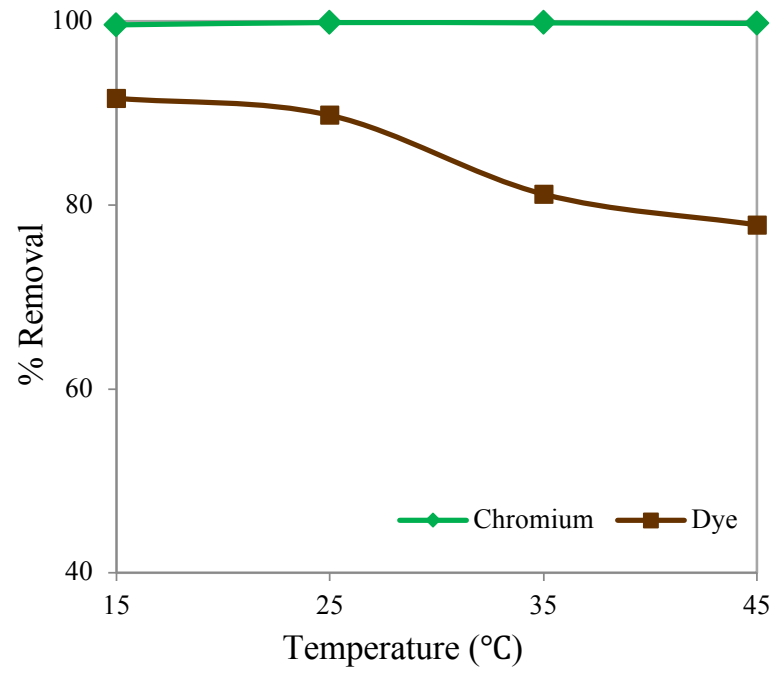

(e)

Fig. 5: Effect of (a) adsorbent dosage, (b) initial solution pH, (c) initial concentration of $\mathrm{Cr}$ (III) and dye, (d) contact time and (e) temperature on $\mathrm{Cr}$ (III) and dye removal 


\subsubsection{Effect of initial $\mathrm{pH}$ of the solution}

To see the effect of the initial pH of solution on the simultaneous adsorption of contaminants, $15000 \frac{\mathrm{mg}}{\mathrm{L}}$ of CHPTACclay was added to solutions containing $100 \mathrm{mg} / \mathrm{L}$ of each contaminant with the pHs of 3,4 and 5 , and a contact time of $2 \mathrm{hr}$ was given. The results are depicted in Figure 5 (b). As it can be seen in this figure, the initial pH of the solutions had no significant impact on the removal of dye, but for $\mathrm{Cr}$ (III), the removal was slightly higher in $\mathrm{pH}=4$. In $\mathrm{pHs}$ of 3 and 4, $\mathrm{Cr}$ (III) is in the forms $\mathrm{Cr}^{3+}$ and $\mathrm{CrOH}^{2+}$ and this cationic species may be adsorbed by the pores of the adsorbent and/or by the hydroxide groups on the adsorbent surface. In the pH of $5, \mathrm{Cr}(\mathrm{OH})_{2}^{+}$and $\mathrm{Cr}(\mathrm{OH})_{3}^{0}$ species are also present in the solution and $\mathrm{Cr}(\mathrm{OH})_{3}^{0}$ results in precipitation(Richard and Bourg, 1991). In this $\mathrm{pH}$ for $\mathrm{Cr}$ (III), precipitation will occur instead of adsorption. It should be noted that $\mathrm{pHs}$ lower and higher than this range were not investigated in this study since the studied solution is a leather tannery model wastewater, and this is the $\mathrm{pH}$ range present in this industry's wastewater.

\subsubsection{Effect of initial concentration of the solution}

To investigate the effect of the solutions' initial concentration, $15000 \frac{\mathrm{mg}}{\mathrm{L}}$ of the CHPTAC-clay was applied to solutions in $\mathrm{pH}$ of 4 and containing 25 to $300 \mathrm{mg} / \mathrm{L}$ of each contaminant, and a contact time of $2 \mathrm{hr}$ was given. The results are depicted in Figure 5 (c). Based on this figure, $\mathrm{Cr}$ (III) removal efficiencies were higher than $99 \%$ in all the investigated concentrations. For the dye, the initial concentration shows no significant effect on the adsorption capacity, and there was only a slight increase in the removal value in the initial concentration of $100 \mathrm{mg} / \mathrm{L}$. These results show that the adsorbent has enough active sites for the adsorption of contaminants in this wide range of initial concentrations. The reason for no more adsorption of the dye in all these initial concentrations can be attributed to reaching an equilibrium that limits the adsorption capacity to be no more than this.

\subsubsection{Effect of contact time}

To study the effect of contact time, $15000 \frac{\mathrm{mg}}{\mathrm{L}}$ of the CHPTAC-clay was applied to solutions in $\mathrm{pH}$ of 4 and containing $100 \mathrm{mg} / \mathrm{L}$ of each contaminant, and the contact times of 1.5 to $240 \mathrm{~min}$ were given. The results are depicted in Figure 5 (d). As it can be seen in this figure, adsorption of $\mathrm{Cr}$ (III) and dye were completed in the first 3 and 10 to 30 minutes, respectively. The reason for this rapid removal of contaminants is the vacancy of adsorption sites in the adsorbent in the first minutes. After this time, an equilibrium is reached. 


\subsubsection{Effect of temperature}

To study the effect of temperature, $15000 \frac{\mathrm{mg}}{\mathrm{L}}$ of the CHPTAC-clay was applied to solutions in $\mathrm{pH}$ of 4 and containing $100 \mathrm{mg} / \mathrm{L}$ of each contaminant, and a contact time of $120 \mathrm{~min}$ was given. The tests were carried out in water baths with controlled temperatures of 15 to $45^{\circ} \mathrm{C}$. The results are depicted in Figure 5 (e). As it can be seen in this figure, the temperature has no effect on $\mathrm{Cr}$ (III) adsorption but a significant effect on dye adsorption. An increase in temperature leads to a decrease in dye adsorption and it is consistent with typical adsorption cases.

Based on the results of these investigated five steps, the CHPTAC-clay gives promising results in the adsorption of both $\mathrm{Cr}$ (III) and dye. The removal efficiency of Cr (III) using U-clay was adequate, but adsorption of the dye using the raw clay was so negligible, and this alteration leads to high values of dye removal.

\subsection{The ratio of binary adsorption capacities and adsorption selectivity}

Comparing the adsorption capacity values obtained for each contaminant in single and binary solutions, it was accepted that both antagonistic and synergistic adsorption was observed in the simultaneous removal of contaminants. This result is seen in Figure 6 (a) and Figure 6 (b) that show the adsorption capacities of contaminants in single and binary solutions. Investigating the $R_{q, i}$ for the dye, in the concentration of $25 \mathrm{mg} / L, R_{q, i}=1.0167$ that can be assumed to be equal to 1 . There are two possible explanations for this: (1) $\mathrm{Cr}$ (III) is adsorbed on the active sites and provides a positively charged surface, preparing the surface to adsorb negatively charged dye via electrostatic attraction forces, the positive surface created by the adsorption of $\mathrm{Cr}$ (III) acts more effective in the adsorption of dye than the vacant active sites of the adsorbent, which may be due to spontaneity of $\mathrm{Cr}$ (III) adsorption and non-spontaneity of dye adsorption, (2) in this low concentration there are enough active sites for both contaminants and they show no synergistic or antagonistic effects in adsorption. When the concentrations of contaminants increase up to $100 \mathrm{mg} / \mathrm{L}$, the $R_{q, i} \mathrm{~s}$ are less than 1 indicating that $\mathrm{Cr}$ (III) occupies the active sites and limits dye adsorption. In concentrations of 150 and $200 \mathrm{mg} / \mathrm{L}, R_{q, i} \mathrm{~S}$ are more than 1 , indicating that $\mathrm{Cr}$ (III) occupies the active sites and provides more positive charged groups, thus creating more adsorption sites for the dye due to electrostatic attraction forces. In concentration of $300 \mathrm{mg} / L$, the $R_{q, i}$ is less than 1 , in this concentration, the condition explained for the concentrations of 150 and $200 \mathrm{mg} / \mathrm{L}$ is still established and the positively charged surface helps, and much higher dye adsorption occurs, and this is due to a much higher $q_{s, i}$ that $R_{q, i}$ becomes less than 1 (Deng et al., 2013). 
For $\mathrm{Cr}$ (III) adsorption in all the investigated concentrations, $R_{q, i} \mathrm{~s}$ are less than 1 , indicating that $\mathrm{Cr}$ (III) competes with the dye for adsorption sites and if there were no dye contaminations in the solution, the adsorption capacities of $\mathrm{Cr}$ (III) would be much higher, meaning a need for much less adsorbent to remove the $\mathrm{Cr}$ (III) from these solutions. This has been proven thoroughly in our previous work, which studied the removal of $\mathrm{Cr}$ (III) from single solutions using this raw clay.

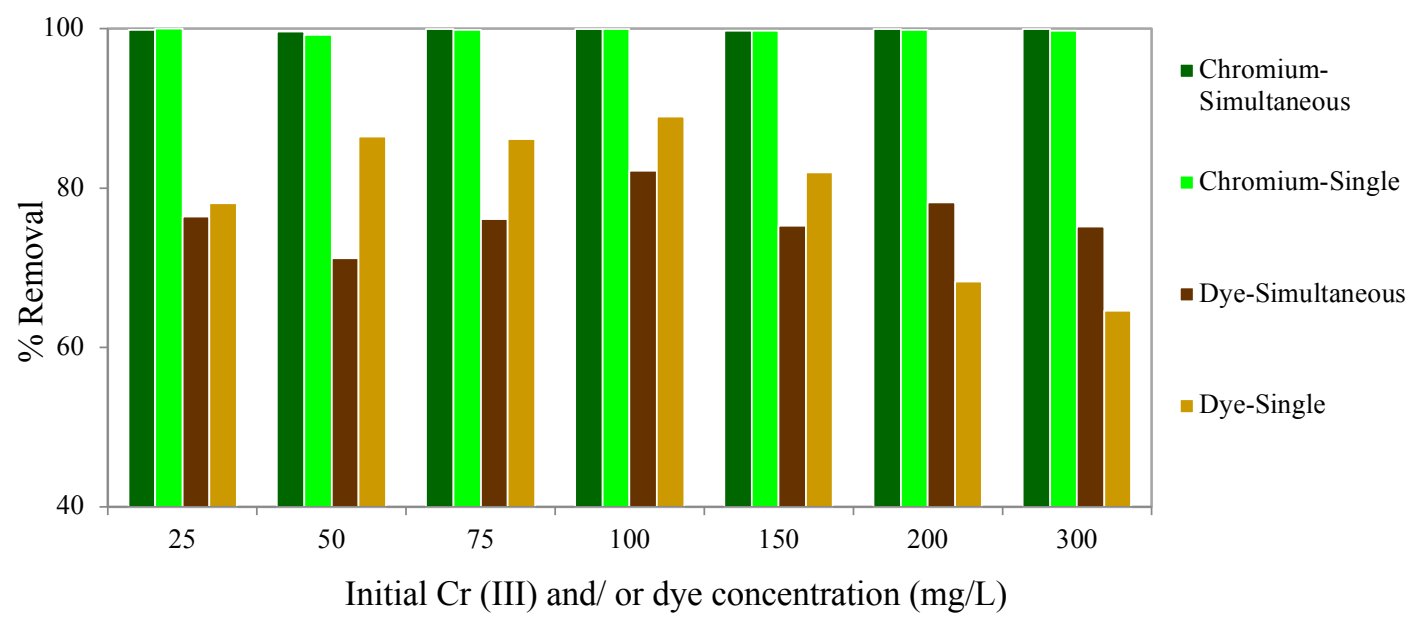

(a)

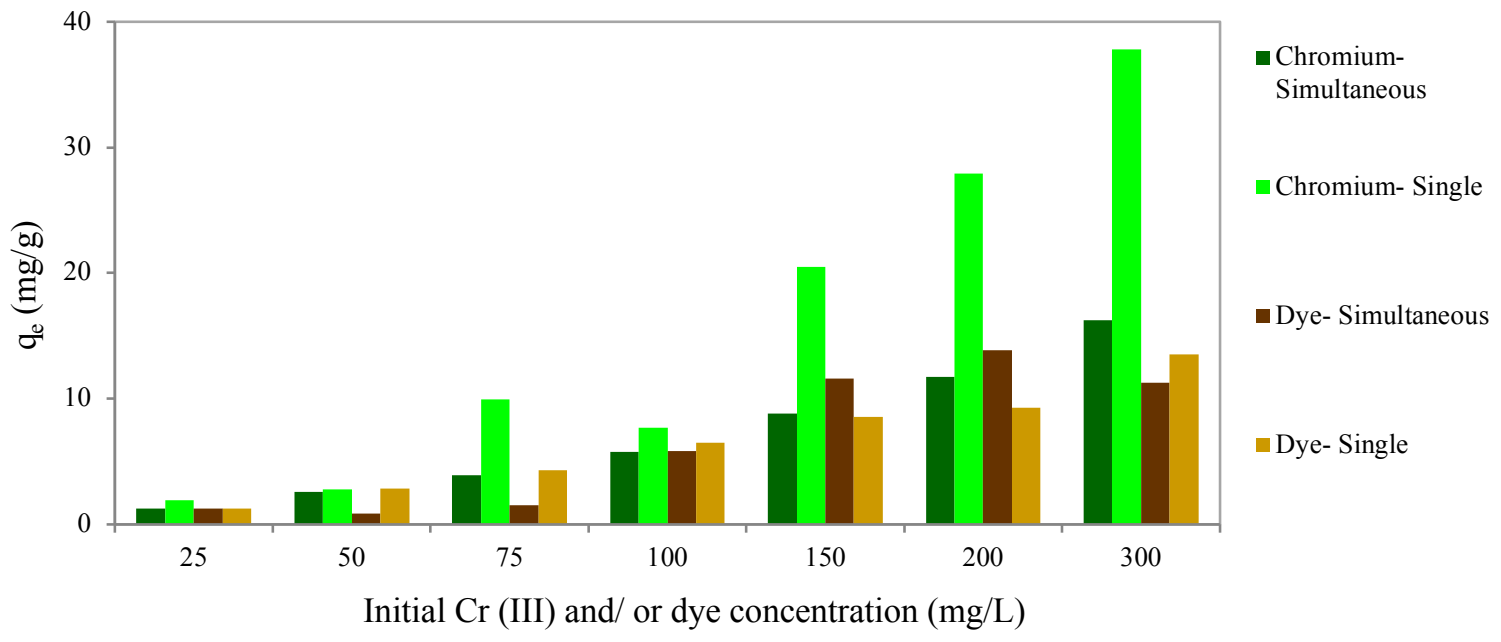

(b)

Fig. 6: Comparison of (a) adsorption efficiencies and (b) adsorption capacities of each contaminant vs. initial concentration of solutions in both single and binary solutions 


\subsection{Kinetic studies}

Based on the results, the data obtained for the simultaneous adsorption of $\mathrm{Cr}$ (III) and dye were fitted to the pseudosecond-order model with $R^{2}=1$ and $R^{2}=0.9999$ for $\mathrm{Cr}$ (III) and dye, respectively. Using Eq.8, initial adsorption velocities are obtained to be $40.725 \mathrm{mg} / \mathrm{g} \mathrm{min}$ for $\mathrm{Cr}$ (III) and $28.2633 \mathrm{mg} / \mathrm{g} \mathrm{min}$ for dye.

\subsection{Isotherm studies}

Based on the calculations (SM, Tables 1, 2, 3 and 4), it was found that the adsorption of Cr (III) from a single and a binary solution follows D-R and Langmuir isotherms, respectively, and the adsorption of dye from both single and binary solutions follows R-PT isotherm. For adsorption of Cr (III), HYBRID and Chi, and for the adsorption of dye, HYBRID error functions had the minimum error and gave the best fit to the experimental data, respectively. As said above, $\mathrm{Cr}$ (III) adsorption from binary solutions follows Langmuir isotherm. Based on the parameters of this isotherm, it was concluded that the maximum monolayer adsorption capacity of Langmuir for Cr (III) in binary solutions is $193.1390 \mathrm{mg} / \mathrm{g}$. Since $q_{e} \mathrm{~s}$ obtained for the adsorption of $\mathrm{Cr}$ (III) from binary systems in the range investigated are all lower than $q_{m L}$, it is understood that monolayer adsorption processes have been carried out in which the adsorbent surface has not been filled completely (SM, Table 5) (Taty-Costodes et al., 2003). The values of $R_{L}$ parameter shows that the adsorption carried out is a favorable process (SM, Table 6). Based on Eq.16, adsorption energy of Cr (III) from single solutions is obtained to be $0.6983 \mathrm{KJ} / \mathrm{mol}$, which shows that this adsorption process is physical (Sarl, Tuzen and Soylak, 2007). In the adsorption of Cr (III) from both single and binary solutions, the parameter of $\mathrm{g}$ in RPT isotherm was obtained to be 0 , so it can be said that this isotherm follows Henry's law, and in the single solution

of dye, $a_{R} C_{e}^{g} \gg 1$, so it can be noted that Freundlich isotherm is applied to the system (Vijayaraghavan et al., 2006; Liu and Liu, 2008).

\subsection{Thermodynamic studies}

For $\mathrm{Cr}$ (III) adsorption from binary solutions, thermodynamic parameters were calculated to be -17.4893 and -0.0272 $\mathrm{KJ} / \mathrm{mol}$ for $\Delta H^{\circ}$ and $\Delta S^{\circ}$, respectively, and for dye $\Delta H^{\circ}$ and $\Delta S^{\circ}$ are 31.3305 and $-0.1109 \mathrm{KJ} / \mathrm{mol}$, respectively. In temperatures of $15,25,35$ and $45^{\circ} \mathrm{C},-9.5877,-9.4683,-9.2060$ and $-8.7551 \mathrm{KJ} / \mathrm{mol}$ were the values of $\Delta G^{\circ}$ for $\mathrm{Cr}$ (III) adsorption process and $0.7592,1.3309,3.1918$ and $3.8396 \mathrm{KJ} / \mathrm{mol}$ were the values obtained for $\Delta G^{\circ}$ of the dye adsorption process. Based on the results, it was found that the adsorption process is spontaneous for $\mathrm{Cr}$ (III) removal 
but non-spontaneous for dye removal. Cr (III) adsorption is exothermic, while adsorption of dye was obtained to be endothermic. Entropy is also decreasing when both contaminants are adsorbed on the adsorbent.

\section{7. $\mathrm{RSM}$ results}

By applying the multivariate regression model on the CCF design and Table 3, quadratic equations for predicting the adsorption capacities of each contaminant are obtained:

$$
\begin{aligned}
& \operatorname{Ln}\left(Y_{1}\right)=2.89+0.74 x_{1}+0.016 x_{2}+0.28 x_{1} x_{2}-0.77 x_{1}^{2}+0.29 x_{2}^{2} \\
& \operatorname{Ln}\left(Y_{2}\right)=1.93-0.16 x_{1}+0.78 x_{2}+0.024 x_{1} x_{2}-0.066 x_{1}^{2}-0.38 x_{2}^{2}
\end{aligned}
$$

Where $Y_{1}$ and $Y_{2}$ are the predicted values of the adsorption capacities for the $\mathrm{Cr}$ (III) and dye $(\mathrm{mg} / \mathrm{g}$ ). The negative and positive coefficients of the model are representatives of antagonistic and synergistic effects in the adsorption, respectively (Yetilmezsoy, Demirel and Vanderbei, 2009). Table 3 shows the observed and predicted values of the adsorption capacities and the error percentages. 
Table 3: Observed, predicted and error values of CCF design

\begin{tabular}{|c|c|c|c|c|c|c|c|c|}
\hline \multirow{2}{*}{$\begin{array}{l}\text { Run. } \\
\text { No }\end{array}$} & \multicolumn{2}{|c|}{$\begin{array}{l}\text { Coded } \\
\text { variable }\end{array}$} & \multicolumn{2}{|c|}{$\begin{array}{l}\text { Adsorption capacity of } \\
\qquad \mathrm{Cr}^{3+}(\mathrm{mg} / \mathrm{g})\end{array}$} & \multicolumn{2}{|c|}{$\begin{array}{c}\text { Adsorption capacity of } \\
\text { dye }(\mathrm{mg} / \mathrm{g})\end{array}$} & \multirow{2}{*}{$\begin{array}{l}\text { Error of } \\
\mathrm{Cr}^{3+}(\%)\end{array}$} & \multirow{2}{*}{$\begin{array}{l}\text { Error of } \\
\text { dye }(\%)\end{array}$} \\
\hline & $x_{1}$ & $x_{2}$ & Observed & Predicted & Observed & Predicted & & \\
\hline 1 & -1 & -1 & 7.3731 & 6.9171 & 2.7390 & 2.4303 & 6.1843 & 11.2718 \\
\hline 2 & 1 & 1 & 35.7525 & 31.3746 & 7.8209 & 8.3980 & 12.2449 & -7.3796 \\
\hline 3 & -1 & 0 & 3.3151 & 3.9749 & 6.4963 & 7.5685 & -199029 & -16.5054 \\
\hline 4 & 0 & -1 & 19.7633 & 23.6651 & 1.8351 & 2.1598 & -19.7425 & -17.6920 \\
\hline 5 & -1 & 1 & 4.5024 & 4.0796 & 11.2488 & 11.0232 & 9.3904 & 2.0058 \\
\hline 6 & 1 & -1 & 19.3252 & 17.3571 & 1.7333 & 1.6820 & 10.1843 & 2.9581 \\
\hline 7 & 0 & 1 & 19.2367 & 24.4346 & 10.9080 & 10.2779 & -27.0207 & 5.7761 \\
\hline 8 & 1 & 0 & 13.7726 & 17.4615 & 5.7562 & 5.4959 & -26.7845 & 4.5223 \\
\hline 9 & 0 & 0 & 19.6039 & 17.9933 & 7.0286 & 6.8895 & 8.2157 & 1.9789 \\
\hline 10 & 0 & 0 & 19.6033 & 17.9933 & 7.0087 & 6.8895 & 8.2128 & 1.7006 \\
\hline 11 & 0 & 0 & 19.6036 & 17.9933 & 7.0186 & 6.8895 & 8.2143 & 1.8392 \\
\hline 12 & 0 & 0 & 19.6039 & 17.9933 & 7.0097 & 6.8895 & 8.2157 & 1.7146 \\
\hline 13 & 0 & 0 & 19.6039 & 17.9933 & 7.0180 & 6.8895 & 8.2157 & 1.8309 \\
\hline
\end{tabular}

Analysis of variance (ANOVA) results, shown in Tables 4 and 5 for $\mathrm{Cr}$ (III) and dye, were used to evaluate the significance of the quadratic equations fitted to the experimental data. The significance of each coefficient is determined via probability values (P-value) shown in Tables 4 and 5. Low P-values confirm that the parameter in the model is significant. In the simultaneous adsorption of the $\mathrm{Cr}$ (III) and dye, first and second-order factors of $\mathrm{Cr}$ (III) concentration and interactive effects of $\mathrm{Cr}$ (III) and dye concentrations are significant. In dye adsorption, the firstorder factor of $\mathrm{Cr}$ (III) concentration and dye's first and second-order factors are substantial. P-values of the given quadratic models also show the significance of models. High values of the regression coefficients and the adjusted regression coefficients of the models $\left(R^{2}=0.9534,0.9825\right.$ for $\mathrm{Cr}(\mathrm{III})$ and dye, respectively, $R_{a}^{2}=0.9201,0.9701$ for $\mathrm{Cr}$ (III) and dye, respectively) also show the significance of the models. The graphs depicted based on the results of models obtained show that in the graphs of the predicted values vs. the actual values and in normal probability 
plots, the points are close to the diagonal line, meaning that the variations of the experimental and predicted values are minor and the models are highly significant (SM, Figures 1 and 2).

Table 4: ANOVA for adsorption of Cr (III)

\begin{tabular}{|c|c|c|c|c|c|c|}
\hline \multirow{2}{*}{ Factors (coded) } & \multicolumn{6}{|l|}{ Statistics $^{\mathrm{a}}$} \\
\hline & $\mathrm{SS}^{\mathrm{b}}$ & & $d f^{c}$ & $\mathrm{MSS}^{\mathrm{d}}$ & F-value $e^{e}$ & P-value Prob $>$ F \\
\hline Model & 5.27 & & 5 & 1.05 & 28.64 & 0.0002 \\
\hline$x_{1}$ & 3.31 & & 1 & 3.31 & 89.98 & $<0.0001^{\mathrm{f}}$ \\
\hline$x_{2}$ & $1.5 \times 10^{-3}$ & & 1 & $1.5 \times 10^{-3}$ & 0.041 & 0.8457 \\
\hline$x_{1} x_{2}$ & 0.31 & & 1 & 0.31 & 8.34 & $0.0234^{\mathrm{f}}$ \\
\hline$x_{1}^{2}$ & 1.65 & & 1 & 1.65 & 44.81 & $0.0003^{\mathrm{f}}$ \\
\hline$x_{2}^{2}$ & 0.23 & & 1 & 0.23 & 6.16 & $0.0421^{\mathrm{f}}$ \\
\hline Residual & 0.26 & & 7 & 0.037 & & \\
\hline \multirow[t]{2}{*}{ Pure Error } & $S S_{E}=7.5$ & $\times$ & 4 & $M S S_{E}=1.9 \times 10^{-10}$ & & \\
\hline & $10^{-10}$ & & & & & \\
\hline Total & 5.53 & & 12 & & & \\
\hline
\end{tabular}

${ }^{a} \mathrm{E}$ is the subscript indicating the error.

${ }^{\mathrm{b}}$ Sum of squares.

${ }^{\mathrm{c}}$ Degree of freedom.

${ }^{\mathrm{d}}$ Mean of squares $\left(M S S=S S / d f, M S S_{E}=S S_{E} / d f_{E}\right)$.

${ }^{\mathrm{e}} \mathrm{F}$-value $=M S S / M S S_{E}$

${ }^{\mathrm{f}} \mathrm{P}$-values $<0.05$ were considered to be significant. 
Table 5: ANOVA for adsorption of dye

\begin{tabular}{llllll}
\hline \multirow{2}{*}{ Factors (coded) } & \multicolumn{2}{l}{ Statistics } & & & \\
\cline { 2 - 6 } & $\mathrm{SS}$ & $\mathrm{df}$ & MSS & F-value & P-value Prob $>$ F \\
\hline Model & 4.73 & 5 & 0.87 & 78.75 & $<0.0001$ \\
& & & & & \\
$x_{1}$ & 0.15 & 1 & 0.15 & 13.31 & 0.0082 \\
$x_{2}$ & 3.68 & 1 & 3.68 & 331.73 & $<0.0001$ \\
$x_{1} x_{2}$ & 0.0002 & 1 & 0.0002 & 0.20 & 0.6688 \\
$x_{1}^{2}$ & 0.012 & 1 & 0.012 & 1.09 & 0.3317 \\
$x_{2}^{2}$ & 0.40 & 1 & 0.40 & 35.64 & 0.0006 \\
& & & & & \\
Residual & 0.078 & 7 & 0.011 & & \\
Pure Error & $S S_{E}=5.3 \times 10^{-6}$ & 4 & $M S S_{E}=1.3 \times 10^{-6}$ & & \\
Total & 4.45 & 12 & & & \\
\hline
\end{tabular}

To study the effects of independent variables and their interactive effects, three-dimensional response surfaces and contour plots (Figures 7) were obtained based on Eq.23 and Eq.24. Based on this figure, it was concluded that an increase in the concentration of each contaminant leads to a rise in its adsorption, while an increase in the concentration of each contaminant has no significant effect on the adsorption of other contaminants. 


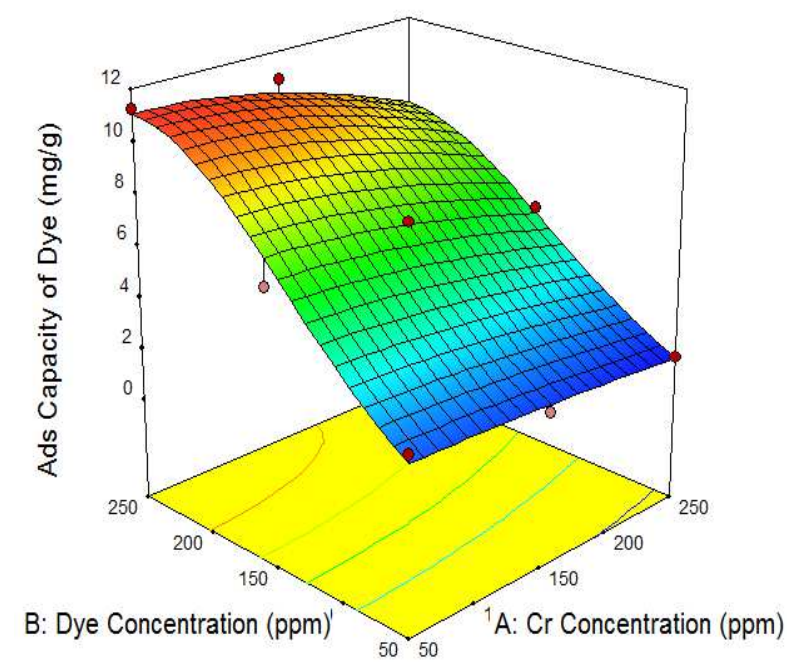

(a)

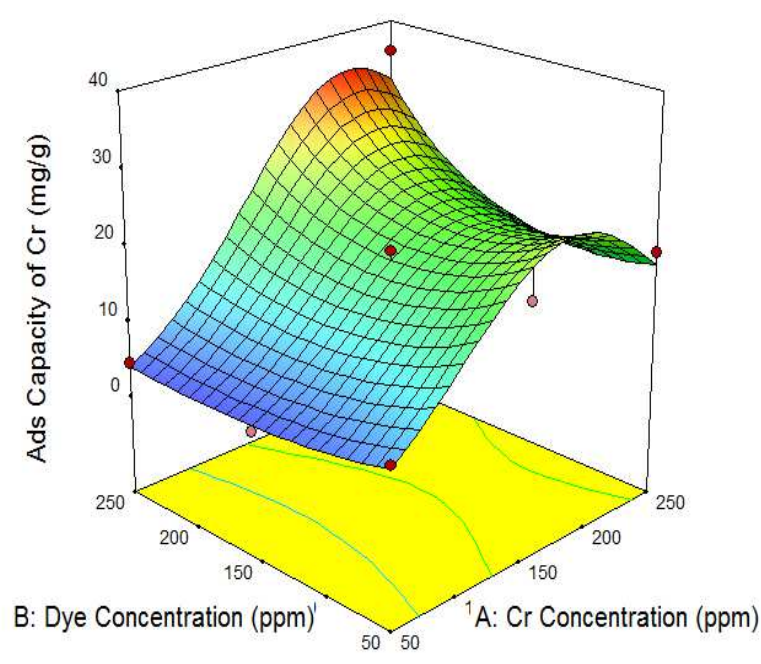

(b)

Fig. 7: 3D response surface diagrams and contour plots (a) Adsorption capacity of dye (mg/L) and (b)

\section{Adsorption capacity of $\mathrm{Cr}$ (III) (mg/L)}

\subsection{Study of the adsorption mechanism}

It is well known that clay minerals have a negative surface charge (Liu et al., 2016; Oskui, Aghdasinia and Sorkhabi, 2019a). In a previous paper carried out by the authors that thoroughly investigated the $\mathrm{Cr}^{3+}$ on the U-clay, adsorption was studied in an acidic $\mathrm{pH}$ range. The results showed that a lower $\mathrm{pH}, \mathrm{H}^{+}$concentration increases and the $\mathrm{Cr}^{3+}$ adsorption decreases due to competitive adsorption between $\mathrm{H}^{+}$and $\mathrm{Cr}^{3+}$ cations on the surface hydroxyl groups. So, it was concluded that high adsorption of $\mathrm{Cr}^{3+}$ is due to the electrostatic attraction between $\mathrm{Cr}$ (III) cations and negatively charged clay framework (Gładysz-Płaska et al., 2012). The same mechanism is believed to be responsible for the adsorption of $\mathrm{Cr}^{3+}$ on CHPTAC-clay. Adsorption of $\mathrm{Cr}^{3+}$ on clay can also be contributed to ion exchange (Liu et al., 2016; Wang et al., 2017).

In this work, at first, acidic dye adsorption tests were carried out by the U-clay, and it showed almost zero efficiencies. This is believed to be due to similar ions in acidic dye and clay surfaces. So, the organic modifier was intercalated into the interlayers of U-clay via Van der Waals forces, and the modified clay showed a significant increase in dye adsorption (Gładysz-Płaska et al., 2012). Thus, it was understood that the surfactant was successfully introduced into the clay. Based on the previous studies in the literature using different surfactants, the surface properties of U-clay 
could have changed from hydrophilic to hydrophobic when this organic molecules were intercalated into the interlayer space of U-clay and high adsorption of dye occurred through hydrophobic interaction between dye and alkyl ammonium chains (Wang et al., 2017).

\subsection{Comparison of the results with literature data}

For further comparison with other studies, the adsorption data obtained from literature in different papers carried out on the simultaneous adsorption of a heavy metal and a dye or an organic contaminant via surfactant modified clays are gathered in a table 6 .

Complete investigation of $\mathrm{Cr}$ (III) adsorption via non-modified U-clay was previously carried out by the authors (Oskui, Aghdasinia and Sorkhabi, 2019a, 2019b). To prevent the repetition and making this paper lengthy, that data are not brought in this paper again. Various tests were also carried out on the adsorption of dye by non-modified U-

clay, but the non-modified U-clay showed very low adsorption capacity for the acid brown dye. That is the reason why, authors investigated the U-clay modification using CHPTAC surfactant.

It should be noted that, obviously, the real wastewater of the leather tannery industry is a multi-component sample. Still, we have to do step by step experimental studies for a better understanding of the process and the mechanism. And that is the reason why model wastewater containing only $\mathrm{Cr}$ (III) and dye was used in this step of the study. Carrying out the experiments using real samples, columnar studies, doing other modifications to this clay and clay granulation to approach the pilot scales are the next steps of authors' studies in hand. 
Table 6: Comparison of the results with literature dat

\begin{tabular}{|c|c|c|c|c|c|c|}
\hline & $\begin{array}{c}\text { (Gładysz-Płaska et al., } \\
\text { 2012) }\end{array}$ & (Fan et al., 2014) & (Wang et al., 2017) & (Liu et al., 2016) & (Ma et al., 2016) & \\
\hline Contaminants & $\mathrm{Cr}(\mathrm{VI})$ and phenol & $\begin{array}{l}C u^{2+} \text { and methylene } \\
\text { blue }\end{array}$ & $\mathrm{Zn}^{2+}$ and phenol & $C d^{2+}$ and BPA & $\begin{array}{c}\mathrm{Cu}(\mathrm{II}) \text { and } \\
\text { phenol }\end{array}$ & $\begin{array}{l}\mathrm{Cr} \text { (III) and acid } \\
\text { brown }\end{array}$ \\
\hline Adsorbent & Natural red clay & Montmorillonite & Montmorillonite & Montmorillonite & Montmorillonite & U-clay \\
\hline The modifier used & HDTMA & SB12 & $\begin{array}{c}\text { CSH, TTAC, CTAC, } \\
\text { STAC }\end{array}$ & BS-18 & $\begin{array}{l}\text { Cationic } \\
\text { HDTMA (C16) } \\
\text { and zwitterionic } \\
\text { Z16 surfactants }\end{array}$ & CHPTAC \\
\hline Adsorbent dosage & $\frac{0.4 \mathrm{~g}}{100 \mathrm{ml}}$ & $\frac{0.05 \mathrm{~g}}{50 \mathrm{ml}}$ & $\frac{0.4 \mathrm{~g}}{40 \mathrm{ml}}$ & $\frac{0.05 \mathrm{~g}}{25 \mathrm{ml}}$ & $\frac{0.1 \mathrm{~g}}{20 \mathrm{ml}}$ & $\frac{1.5 \mathrm{~g}}{100 \mathrm{ml}}$ \\
\hline Solution initial pH & 5.5 & 5 & 11 & 4 & 5 & 4 \\
\hline $\begin{array}{l}\text { Solution initial } \\
\text { concentration }\end{array}$ & $\begin{array}{l}0.2 \frac{\mathrm{mmol}}{\mathrm{dm}^{3}} \text { for } \mathrm{Cr}(\mathrm{VI}) \\
0.6 \frac{\mathrm{mmol}}{\mathrm{dm}^{3}} \text { for phenol }\end{array}$ & $\begin{array}{c}\mathrm{Cu}^{2+}=15 \frac{\mathrm{mg}}{\mathrm{L}} \text { and } \mathrm{MB}=0 \\
\text { to } 330 \frac{\mathrm{mg}}{\mathrm{L}} \\
\mathrm{MB}=250 \frac{\mathrm{mg}}{\mathrm{L}} \text { and } \\
\mathrm{Cu}^{2+}=0 \text { to } 32 \frac{\mathrm{mg}}{\mathrm{L}}\end{array}$ & $40 \frac{\mathrm{mg}}{\mathrm{L}}$ & $\begin{array}{l}C d^{2+}=40 \frac{m g}{L} \\
\mathrm{BPA}=10 \frac{m g}{L}\end{array}$ & $\begin{array}{l}60 \frac{m g}{L} \text { for } \mathrm{Cu}(\mathrm{II}) \\
150 \frac{\mathrm{mg}}{\mathrm{L}} \text { for phenol }\end{array}$ & $100 \frac{\mathrm{mg}}{\mathrm{L}}$ \\
\hline Contact time (min) & 360 & Not reported & 10 & 1440 & 30 & 30 \\
\hline Temperature $\left({ }^{\circ} \mathrm{C}\right)$ & Room temperature & Not reported & Higher temperatures & 30 & 25 & 15 \\
\hline Isotherm model & $\begin{array}{l}\text { Langmuir-Freundlich } \\
\text { for Cr (VI) } \\
\text { Dual site Langmuir- } \\
\text { Freundlich for phenol }\end{array}$ & Not reported & Freundlich & $\begin{array}{l}\text { Freundlich for } \\
\qquad d^{2+} \\
\text { Langmuir for } \\
\text { BPA }\end{array}$ & $\begin{array}{c}\text { Langmuir for } \mathrm{Cu} \\
\text { (II) } \\
\text { Linear equation } \\
\text { for phenol }\end{array}$ & $\begin{array}{c}\text { Langmuir for } \mathrm{Cr} \\
\text { (III) } \\
\text { Redlich-Peterson } \\
\text { for dye }\end{array}$ \\
\hline Kinetic model & First order & Not reported & Not reported & $\begin{array}{c}\text { Pseudo-second } \\
\text { order }\end{array}$ & $\begin{array}{l}\text { Pseudo-second } \\
\text { order }\end{array}$ & $\begin{array}{c}\text { Pseudo-second } \\
\text { order }\end{array}$ \\
\hline $\begin{array}{c}\text { Maximum } \\
\text { adsorption capacity }\end{array}$ & $\begin{array}{l}0.086 \frac{\mathrm{mmol}}{\mathrm{g}} \text { for } \mathrm{Cr}(\mathrm{VI}) \\
0.012 \frac{\mathrm{mmol}}{\mathrm{g}} \text { for phenol }\end{array}$ & $\begin{array}{l}9.5 \frac{m g}{g} \text { for } C u^{2+} \\
150.2 \frac{m g}{g} \text { for } \mathrm{MB}\end{array}$ & Not reported & $\begin{array}{c}42.11 \frac{\mathrm{mg}}{g} \text { for } \\
C d^{2+} \\
80.77 \frac{\mathrm{mg}}{g} \text { for BPA }\end{array}$ & $\begin{array}{l}14.12 \frac{m g}{g} \text { via Z16- } \\
\text { Mt for Cu (II) } \\
3.75 \frac{\mathrm{mg}}{\mathrm{g}} \text { via C16- } \\
\text { Mt for } \mathrm{Cu} \text { (II) }\end{array}$ & $\begin{array}{l}193.1390 \frac{\mathrm{mg}}{\mathrm{g}} \text { for } \\
\text { Cr (III) } \\
\begin{array}{c}144.1782 \frac{\mathrm{mg}}{\mathrm{g}} \\
\text { dye }\end{array}\end{array}$ \\
\hline Removal efficiency & $\begin{array}{l}90 \% \text { for } \mathrm{Cr}(\mathrm{VI}) \\
8 \% \text { for phenol }\end{array}$ & Not reported & $\begin{array}{c}100 \%\left(3.99 \frac{\mathrm{mg}}{\mathrm{g}}\right) \text { for } \\
Z n^{2+} \\
65.5 \%\left(2.62 \frac{\mathrm{mg}}{\mathrm{g}}\right) \text { for } \\
\text { phenol }\end{array}$ & Not reported & Not reported & $\begin{array}{c}99.74 \% \text { for } \\
\text { Cr(III) } \\
83.26 \% \text { for dye }\end{array}$ \\
\hline
\end{tabular}




\section{Conclusions}

Local nano clay modified via CHPTAC surfactant was used to simultaneously remove Cr (III) and acidic dye from model tannery wastewaters. The results showed that simultaneous adsorption of contaminants from a solution with $\mathrm{pH}$ of 4 , containing $100 \mathrm{mg} / \mathrm{L}$ of each contaminant, using $15000 \frac{\mathrm{mg}}{\mathrm{L}}$ of the modified adsorbent, in contact time of 3 $\min$ for $\mathrm{Cr}$ (III) and $30 \mathrm{~min}$ for dye, reached its maximum value $\mathrm{q}_{\mathrm{e}}=6.63151 \mathrm{mg} / \mathrm{g},(\mathrm{Cr})$ and $\mathrm{q}_{\mathrm{e}}=5.61194 \mathrm{mg} / \mathrm{g}$ (dye). Synergistic and antagonistic adsorptions were observed in the binary solutions. The results of kinetic models' studies demonstrated that simultaneous adsorption of contaminants follows the pseudo-second-order model. The results of isotherms' studies showed that the adsorption of $\mathrm{Cr}$ (III) from a binary solution and a single solution follows Langmuir and D-R isotherm. The adsorption of dye from both single and binary solutions follows the R- PT isotherm. Based on the thermodynamic results, the adsorption process of $\mathrm{Cr}$ (III) is spontaneous, and the adsorption process of dye is non-spontaneous. Cr (III) adsorption is exothermic, while adsorption of dye is endothermic. Entropy also decreases when both contaminants are adsorbed on the adsorbent. It was understood from the results of the RSM that an increase in the concentration of $\mathrm{Cr}$ (III) and dye leads to an increase in the adsorption capacities of $\mathrm{Cr}$ (III) and dye, respectively. In contrast, this increase in the concentration of $\mathrm{Cr}$ (III) and the dye had a negligible effect on the adsorption of the other contaminant.

\section{Declarations}

\subsection{Funding}

No funding was received to assist with the preparation of this manuscript.

No funding was received for conducting this study.

No funds, grants, or other support was received.

\subsection{Conflicts of interest/Competing interests}

The authors have no relevant financial or non-financial interests to disclose.

The authors have no conflicts of interest to declare that are relevant to the content of this article.

All authors certify that they have no affiliations with or involvement in any organization or entity with any financial interest or non-financial interest in the subject matter or materials discussed in this manuscript.

The authors have no financial or proprietary interests in any material discussed in this article. 


\section{References}

Adikary, S. U. and Wanasinghe, D. D. (2012) 'Characterization of locally available Montmorillonite clay using FTIR technique', Annual Transactions of Institution of Engineers Sri Lanka, 1(part B), pp. 140-145.

Aghdasinia, H. and Asiabi, H. R. (2018) 'Adsorption of a cationic dye (methylene blue) by Iranian natural clays from aqueous solutions: equilibrium, kinetic and thermodynamic study', Environmental earth sciences. Springer, 77(5), p. 218.

Ahmad, A. et al. (2015) 'Recent advances in new generation dye removal technologies: novel search for approaches to reprocess wastewater', RSC Advances. Royal Society of Chemistry, 5(39), pp. 30801-30818.

Allen, S. J. et al. (2003) 'Comparison of optimised isotherm models for basic dye adsorption by kudzu', Bioresource technology. Elsevier, 88(2), pp. 143-152.

Behnamfard, A. et al. (2019) 'The effect of thermal and acid treatment of kaolin on its ability for cyanide removal from aqueous solutions', Environmental Earth Sciences. Springer, 78(14), p. 408.

Çakmak, M. et al. (2017) 'Removal of astrazon golden yellow 7GL from colored wastewater using chemically modified clay', Journal of Central South University. Springer, 24(4), pp. 743-753.

Deng, J.-H. et al. (2013) 'Simultaneous removal of Cd (II) and ionic dyes from aqueous solution using magnetic graphene oxide nanocomposite as an adsorbent', Chemical Engineering Journal. Elsevier, 226, pp. 189-200.

El-Ashtoukhy, E.-S., Amin, N. K. and Abdelwahab, O. (2008) 'Removal of lead (II) and copper (II) from aqueous solution using pomegranate peel as a new adsorbent', Desalination. Elsevier, 223(1-3), pp. 162-173.

Elmoubarki, R. et al. (2015) 'Adsorption of textile dyes on raw and decanted Moroccan clays: Kinetics, equilibrium and thermodynamics', Water Resources and Industry. Elsevier, 9, pp. 1629. doi: 10.1016/j.wri.2014.11.001.

Fan, H. et al. (2014) 'Adsorption of $\mathrm{Cu} 2+$ and methylene blue on dodecyl sulfobetaine surfactantmodified montmorillonite', Applied Clay Science. Elsevier, 95, pp. 150-158.

Fil, B. A., Ozmetin, C. and Korkmaz, M. (2012) 'Cationic dye (methylene blue) removal from aqueous solution by montmorillonite', Bulletin of the Korean Chemical Society. Korean Chemical Society, 33(10), pp. 3184-3190.

Foo, K. Y. and Hameed, B. H. (2010) 'Insights into the modeling of adsorption isotherm systems', Chemical engineering journal. Elsevier, 156(1), pp. 2-10.

Gładysz-Płaska, A. et al. (2012) 'Simultaneous adsorption of chromium (VI) and phenol on natural red clay modified by HDTMA', Chemical Engineering Journal. Elsevier, 179, pp. 140-150.

Hafshejani, L. D. et al. (2015) 'Removal of zinc and lead from aqueous solution by nanostructured cedar leaf ash as biosorbent', Journal of molecular liquids. Elsevier, 211, pp. 448-456.

Hameed, B. H., Mahmoud, D. K. and Ahmad, A. L. (2008) 'Sorption equilibrium and kinetics of 
basic dye from aqueous solution using banana stalk waste', Journal of Hazardous Materials. Elsevier, 158(2-3), pp. 499-506.

Heinz, H. et al. (2017) 'Nanoparticle decoration with surfactants: molecular interactions, assembly, and applications', Surface Science Reports. Elsevier, 72(1), pp. 1-58.

Ho, Y.-S. (2006) 'Review of second-order models for adsorption systems', Journal of hazardous materials. Elsevier, 136(3), pp. 681-689.

El Kassimi, A. et al. (2021) 'Removal of two cationic dyes from aqueous solutions by adsorption onto local clay: experimental and theoretical study using DFT method', International Journal of Environmental Analytical Chemistry. Taylor \& Francis, pp. 1-22.

Keçeci, M., Usta, S. and Uygur, V. (2020) 'Lead adsorption in soils and the effect of soil properties: case study from Turkey’, Environmental Earth Sciences. Springer, 79(18), pp. 1-13.

Khormaei, M. et al. (2007) 'Copper biosorption from aqueous solutions by sour orange residue', Journal of Hazardous Materials. Elsevier, 149(2), pp. 269-274.

Kim, Y. et al. (2004) 'Arsenic removal using mesoporous alumina prepared via a templating method', Environmental science \& technology. ACS Publications, 38(3), pp. 924-931.

Limousin, G. et al. (2007) 'Sorption isotherms: a review on physical bases, modeling and measurement', Applied geochemistry. Elsevier, 22(2), pp. 249-275.

Liu, C. et al. (2016) 'Simultaneous adsorption of $\mathrm{Cd} 2+$ and BPA on amphoteric surfactant activated montmorillonite', Chemosphere. Elsevier, 144, pp. 1026-1032.

Liu, Y. and Liu, Y.-J. (2008) 'Biosorption isotherms, kinetics and thermodynamics', Separation and Purification Technology, 61(3), pp. 229-242. doi: 10.1016/j.seppur.2007.10.002.

Ma, L. et al. (2016) 'Adsorption of phenol and $\mathrm{Cu}$ (II) onto cationic and zwitterionic surfactant modified montmorillonite in single and binary systems', Chemical Engineering Journal. Elsevier, 283, pp. 880-888.

Madejová, J. (2003) 'FTIR techniques in clay mineral studies', Vibrational spectroscopy. Elsevier, 31(1), pp. 1-10.

Namjoufar, M., Farzi, A. and Karimi, A. (2021) 'Removal of Acid Brown 354 from wastewater by aminized cellulose acetate nanofibers: experimental and theoretical study of the effect of different parameters on adsorption efficiency', Water Science and Technology. IWA Publishing, 83(7), pp. 1649-1661.

Niu, Z. et al. (2018) 'Effect of multifactors interaction on competitive adsorption of $\mathrm{Zn} 2+$ and $\mathrm{Cd}$ 2+ by response surface methodology', Environmental earth sciences. Springer, 77(6), p. 244.

Oskui, F. N., Aghdasinia, H. and Sorkhabi, M. G. (2019a) 'Adsorption of Cr (III) using an Iranian natural nanoclay: applicable to tannery wastewater: equilibrium, kinetic, and thermodynamic', Environmental earth sciences. Springer, 78(4), p. 106.

Oskui, F. N., Aghdasinia, H. and Sorkhabi, M. G. (2019b) 'Modeling and optimization of chromium adsorption onto clay using response surface methodology, artificial neural network, and equilibrium isotherm models', Environmental Progress \& Sustainable Energy. Wiley Online 
Library, 38(6), p. e13260.

Pansu, M. and Gautheyrou, J. (2007) Handbook of soil analysis: mineralogical, organic and inorganic methods. Springer Science \& Business Media.

Parimal, S., Prasad, M. and Bhaskar, U. (2010) 'Prediction of equillibrium sorption isotherm: comparison of linear and nonlinear methods', Industrial \& Engineering Chemistry Research. ACS Publications, 49(6), pp. 2882-2888.

Rhoades, J. D. (1983) ‘Cation exchange capacity', Methods of Soil Analysis: Part 2 Chemical and Microbiological Properties. Wiley Online Library, 9, pp. 149-157.

Richard, F. C. and Bourg, A. C. M. (1991) 'Aqueous geochemistry of chromium: a review', Water research. Elsevier, 25(7), pp. 807-816.

Samiey, B. and Toosi, A. R. (2010) 'Adsorption of malachite green on silica gel: Effects of NaCl, pH and 2-propanol', Journal of hazardous materials. Elsevier, 184(1-3), pp. 739-745.

Sarı, A., Tuzen, M. and Soylak, M. (2007) 'Adsorption of Pb (II) and Cr (III) from aqueous solution on Celtek clay', Journal of Hazardous Materials. Elsevier, 144(1-2), pp. 41-46.

Seif, S., Marofi, S. and Mahdavi, S. (2019) 'Removal of Cr 3+ ion from aqueous solutions using $\mathrm{MgO}$ and montmorillonite nanoparticles', Environmental Earth Sciences. Springer, 78(13), p. 377.

Srinivasan, R. (2011) 'Advances in application of natural clay and its composites in removal of biological, organic, and inorganic contaminants from drinking water', Advances in Materials Science and Engineering. Hindawi, 2011.

Stawiński, W. et al. (2017) 'Simultaneous removal of dyes and metal cations using an acid, acidbase and base modified vermiculite as a sustainable and recyclable adsorbent', Science of the Total Environment. Elsevier, 576, pp. 398-408.

Tahir, H., Sultan, M. and Qadir, Z. (2013) 'Physiochemical modification and characterization of bentonite clay and its application for the removal of reactive dyes', International Journal of Chemistry. Canadian Center of Science and Education, 5(3), p. 19.

Taty-Costodes, V. C. et al. (2003) 'Removal of Cd (II) and Pb (II) ions, from aqueous solutions, by adsorption onto sawdust of Pinus sylvestris', Journal of hazardous materials. Elsevier, 105(13), pp. 121-142.

Tovar-Gomez, R. et al. (2012) 'Synergic adsorption in the simultaneous removal of acid blue 25 and heavy metals from water using a Ca (PO3) 2-modified carbon', Journal of hazardous materials. Elsevier, 199, pp. 290-300.

Tovar-Gómez, R. et al. (2015) 'Analysis of synergistic and antagonistic adsorption of heavy metals and acid blue 25 on activated carbon from ternary systems', Chemical Engineering Research and Design. Elsevier, 93, pp. 755-772.

Vijayaraghavan, K. et al. (2006) 'Biosorption of nickel (II) ions onto Sargassum wightii: application of two-parameter and three-parameter isotherm models', Journal of hazardous materials. Elsevier, 133(1-3), pp. 304-308.

Wang, G. et al. (2017) 'Phenol and/or Zn2+ adsorption by single-or dual-cation 
organomontmorillonites', Applied Clay Science. Elsevier, 140, pp. 1-9.

Wang, X. et al. (2016) 'Enhance Cr (VI) removal by quaternary amine-anchoring activated carbons', Journal of the Taiwan Institute of Chemical Engineers. Elsevier, 58, pp. 434-440.

Wong, Y. C. et al. (2004) 'Adsorption of acid dyes on chitosan-equilibrium isotherm analyses', Process Biochemistry. Elsevier, 39(6), pp. 695-704.

Yagub, M. T. et al. (2014) 'Dye and its removal from aqueous solution by adsorption: a review', Advances in colloid and interface science. Elsevier, 209, pp. 172-184.

Yetilmezsoy, K., Demirel, S. and Vanderbei, R. J. (2009) 'Response surface modeling of Pb (II) removal from aqueous solution by Pistacia vera L.: Box-Behnken experimental design', Journal of Hazardous Materials. Elsevier, 171(1-3), pp. 551-562.

Zaroual, Z. et al. (2009) 'Optimizing the removal of trivalent chromium by electrocoagulation using experimental design', Chemical Engineering Journal. Elsevier, 148(2-3), pp. 488-495. 


\section{Supplementary Files}

This is a list of supplementary files associated with this preprint. Click to download.

- SupplementryInformationEnvironmentalEarthSciences.docx 